NASA/TM-2001-210980

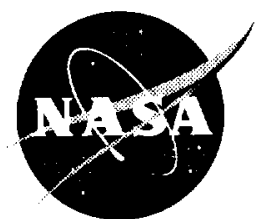

\title{
Further Investigations of Control Surface Seals for the X-38 Re-Entry Vehicle
}

Patrick H. Dunlap, Jr., and Bruce M. Steinetz

Glenn Research Center, Cleveland, Ohio

Donald M. Curry

Johnson Space Center, Houston, Texas

Charles W. Newquist and Juris Verzemnieks

The Boeing Company, Seattle, Washington

Prepared for the

37th Joint Propulsion Conference and Exhibit cosponsored by the AIAA, ASME, SAE, and ASEE

Salt Lake City, Utah, July 8-11, 2001

National Aeronautics and

Space Administration

Glenn Research Center 


\section{Acknowledgments}

The authors greatly acknowledge Jeff Hagen and Prakash Chaudha (Lockheed-Martin) for their contributions in designing the scrub test fixture; Ron Lewis and Winston Goodrich (NASA Johnson Space Center), and

Ignacio Norman (Boeing) for their work on the heat transfer analyses; Jeff DeMange

(Ohio Aerospace Institute) for his assistance in conducting the flow and compression tests; and Tom Doeberling (NASA Glenn Research Center) and Dick Tashjian (QSS) for their assistance in test support.

Trade names or manufacturers' names are used in this report for identification only. This usage does not constitute an official endorsement, either expressed or implied, by the National Aeronautics and Space Administration.

Available from

NASA Center for Aerospace Information 7121 Standard Drive

Hanover, MD 21076
National Technical Information Service 5285 Port Royal Road Springfield, VA 22100 


\title{
FURTHER INVESTIGATIONS OF CONTROL SURFACE SEALS FOR THE X-38 RE-ENTRY VEHICLE
}

\author{
Patrick H. Dunlap. Jr.* \\ Bruce M. Steinetz ${ }^{\dagger}$ \\ National Aeronautics and Space Administration \\ Glenn Research Center \\ Cleveland, $\mathrm{OH}$ \\ Donald M. Curry ${ }^{\ddagger}$ \\ National Aeronautics and Space Administration \\ Johnson Space Center \\ Houston, TX \\ Charles W. Newquist ${ }^{\S}$ \\ Juris Verzemnieks ${ }^{\S}$ \\ The Boeing Company \\ Seattle, WA
}

\begin{abstract}
NASA is currently developing the $\mathrm{X}-38$ vehicle that will be used to demonstrate the technologies required for a potential crew return vehicle (CRV) for the International Space Station. This vehicle would serve both as an ambulance for medical emergencies and as an evacuation vehicle for the Space Station. Control surfaces on the X-38 (body flaps and rudder/fin assemblies) require high temperature seals to limit hot gas ingestion and transfer of heat to underlying low-temperature structures to prevent over-temperature of these structures and possible loss of the vehicle. NASA's Johnson Space Center (JSC) and Glenn Research Center (GRC) are working together to develop and evaluate seals for these control surfaces.

This paper presents results for compression, flow, scrub, and arc jet tests conducted on the baseline X-38 rudder/fin seal design. Room temperature seal compression tests were performed at low compression levels to determine load versus linear compression, preload, contact area, stiffness, and resiliency characteristics under low load conditions. For all compression levels that were tested,

*Mechanical Engineer, Mechanical Components Branch, Member AlAA.

†Senior Research Engineer, Mechanical Components Branch. Member AIAA.

$\ddagger$ Aerospace Technologist, Thermal Branch.

${ }^{\S}$ Ceramics Engineer, Boeing Phantom Works.

Copyright 2001 by the American Institute of Aeronautics and Astronautics, Inc. No copyright is asserted in the United States under Title 17. U.S. Code. The U.S. Government has a royalty-free license to exercise all rights under the copyright claimed herein for Governmental Purposes. All other rights are reserved by the copyright owner.
\end{abstract}

unit loads and contact pressures for the seals were below the $5 \mathrm{lb} / \mathrm{in}$. and $10 \mathrm{psi}$ limits required to limit the loads on the adjoining Shuttle thermal tiles that the seals will contact. Flow rates through an unloaded (i.e., $0 \%$ compression) double seal arrangement were twice those of a double seal compressed to the $20 \%$ design compression level. The seals survived an ambient temperature 1000 cycle scrub test over relatively rough Shuttle tile surfaces. The seals were able to disengage and re-engage the edges of the rub surface tiles while being scrubbed over them. Arc jet tests were performed to experimentally determine anticipated seal temperatures for representative flow boundary conditions (pressures and temperatures) under simulated vehicle re-entry conditions. Installation of a single seal in the gap of the test fixture caused a large temperature drop $\left(1710^{\circ} \mathrm{F}\right)$ across the seal location as compared to an open gap condition $\left(140^{\circ} \mathrm{F}\right)$ confirming the need for seals in the rudder/fin gap location. The seal acted as an effective thermal barrier limiting heat convection through the seal gap and minimizing temperature increases downstream of the seal during maximum heating conditions.

\section{Introduction}

NASA is considering developing a crew return vehicle (CRV) for the International Space Station that would serve both as an ambulance for medical emergencies and as an evacuation vehicle. Astronauts aboard the Space Station would use the CRV to return to Earth in the event of a catastrophe aboard the Station or during periods in which the Space Shuttle is unavailable. NASA is currently developing the X-38 vehicle that will demonstrate the technologies required for a potential CRV (Fig. 1a). The $\mathrm{X}-38$ uses a lifting body concept originally developed by 


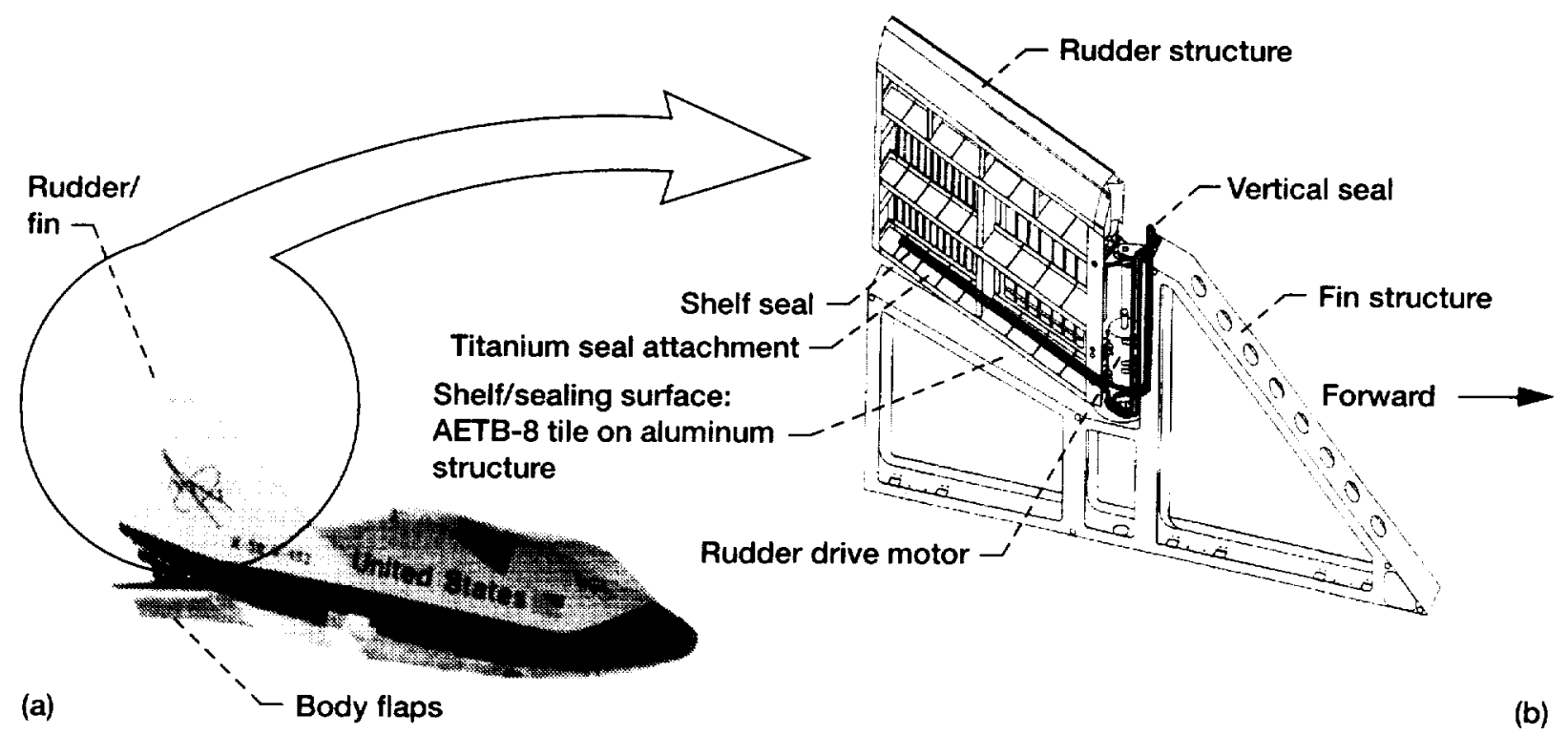

Figure 1.-(a) X-38 vehicle. (b) Rudder/fin structure and seal locations.

the U.S. Air Force's X-24A project in the mid-1960's. ${ }^{1}$ The X-38 also makes use of parachute technology for the landing phase of the return mission previously demonstrated by the Army. Use of this steerable parachute technology for the landing phase eliminates the need for a pilot and simplifies the internal systems of the vehicle. The steerable parachute, or parafoil, and control surfaces of the vehicle allow it to re-enter autonomously under computer control. By combining the knowledge base from each of these programs and adding expertise gained from the Space Shuttle, the X-38 merges many of the technologies required for the CRV missions.

The $\mathrm{X}-38$ vehicle will be carried into space in the Shuttle cargo bay. It will glide from orbit in an unpowered freefall that is controlled by two movable rudders, two bodyflaps located at the aft end of the vehicle, and a steerable parafoil deployed after re-entry (Fig. 1). Seal interfaces exist between the movable bodyflaps and the bottom surface of the vehicle and between the rudders and their respective fins (Figs. $1 \mathrm{a}$ and $\mathrm{lb}$ ). Wong, et al. ${ }^{2}$ performed a series of two-dimensional computational fluid dynamics studies that modeled the gap between the rudder and fin during re-entry of the $\mathrm{X}-38$ vehicle and concluded that a seal is required along this interface to prevent excessive local heat fluxes on these structures. These seals must operate hot and limit hot gas ingestion and transfer of heat to underlying low-temperature structures to prevent over-temperature of these structures and possible loss of the vehicle. Development of the bodyflaps and associated seals is the joint responsibility of MAN Technologie (Germany) and NASA's Johnson Space Center (JSC). JSC and NASA's Glenn Research Center (GRC) are working together to develop and evaluate the rudder/fin seals.

In a previous study, Dunlap et al. ${ }^{3}$ performed a series of experiments to measure flow rates, resiliency, and unit loads for candidate seals for the rudder/fin seal location. They examined these seals in both an as-received state and after temperature exposure to determine the effects that this exposure had on seal performance. A major finding of this study was that exposure of the seals in a compressed state at simulated seal re-entry temperatures resulted in a large permanent set and loss of seal resiliency (Fig. 2). This could be of concern because one of the main requirements for these seals is that they remain in contact with the sealing surfaces while the vehicle goes through the maximum re-entry heating cycle. Good seal contact is required to prevent hot gases from leaking past the seals and into cavities behind them in which low-temperature structures reside. Because of the results of that study,

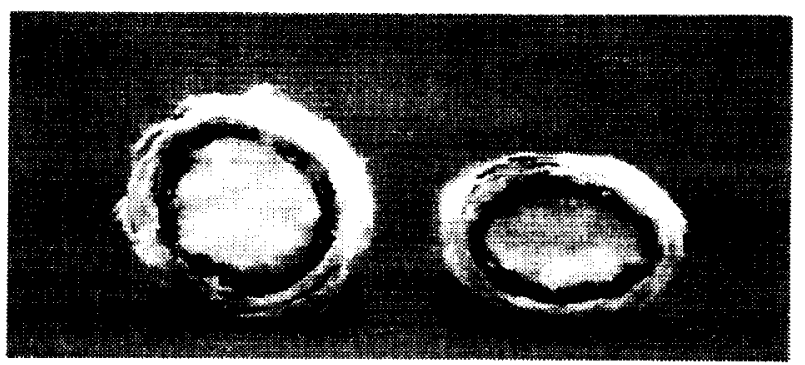

Figure 2.-Photo of $6 \mathrm{pcf} X-38$ seals before and after $1900{ }^{\circ} \mathrm{F}$ temperature exposure. Side-by-side photo of seals before (left) and after (right) temperature exposure. 
it was deemed that additional tests should be done to further characterize the performance of these seals.

The specific objectives of the current study are to:

(1) Measure seal flow rates, resiliency, and unit loads under minimal loads to simulate conditions in which the seals may become unloaded during use. Such conditions may arise if the seals take on a large permanent set due to temperature exposure.

(2) Examine seal durability and wear resistance to recommend rub-surface treatments required to maximize seal wear life.

(3) Experimentally determine anticipated seal temperatures for representative external flow boundary conditions under arc jet test conditions simulating vehicle re-entry.

\section{Design Requirements for X-38 Rudder/Fin Seal System}

The design of the $\mathrm{X}-38$ rudder/fin seal assembly consists of a double seal attached to the rudder that seals the vertical hinge line and the fin shelf line (Figs. 1 and 3). The vertical seal loop surrounds and protects the rudder drive motor and attachments between the rudder and the fin (Fig. 3). The seal assembly must allow the rudder to rotate during the entire mission and must accommodate a rudder/fin deflection range of $\pm 12^{\circ}$ (Fig. 3).

\section{Temperature Limits}

The rudder/fin seal assembly will be expected to endure high temperatures caused by convective heating in an oxidative environment with radiation exchange in the seal gap. A thermal analysis predicted that peak temperatures for the exposed seal could reach approximately $1900^{\circ} \mathrm{F}$ (with laminar boundary layer assumption) to $2100^{\circ} \mathrm{F}$ (with turbulent boundary layer assumption) with seal attachment temperatures of $1500^{\circ} \mathrm{F}$ (Fig. 4). The procedure followed for this analysis is described in detail by Dunlap, et al. ${ }^{3}$ The peak temperatures occur about $1200 \mathrm{sec}(20 \mathrm{~min})$ into re-entry with a subsequent decrease in temperatures for the remainder of the re-entry. Materials used in the seals must be able to withstand these high temperatures. Because the predicted attachment temperature exceeds current adhesive temperature limits. the seals will have to be mechanically attached to the seal attachment bracket and rudder.

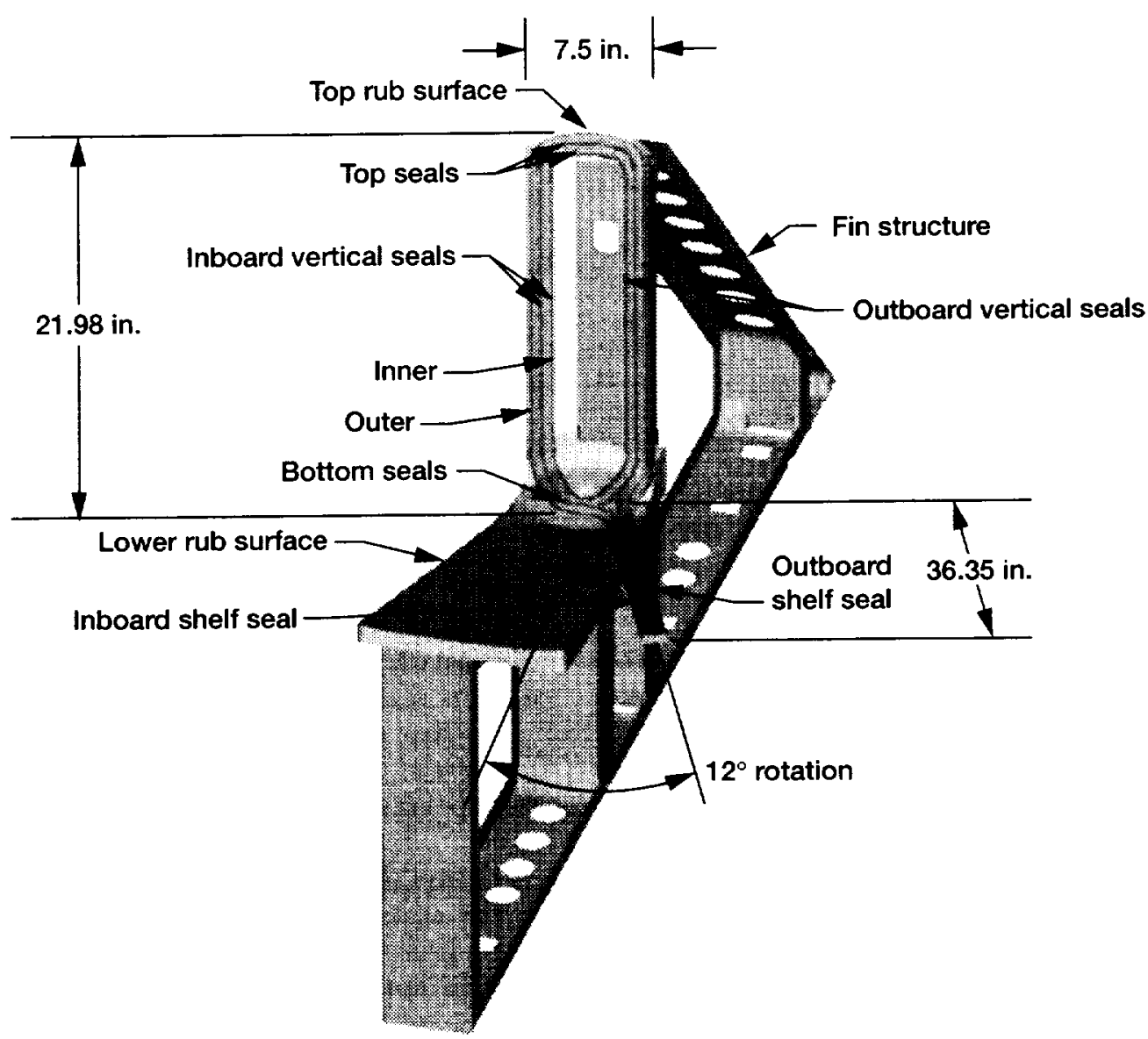

Figure 3.-Computer model depicting rudder/fin seal rotated to full outboard position with seal dimensions. 


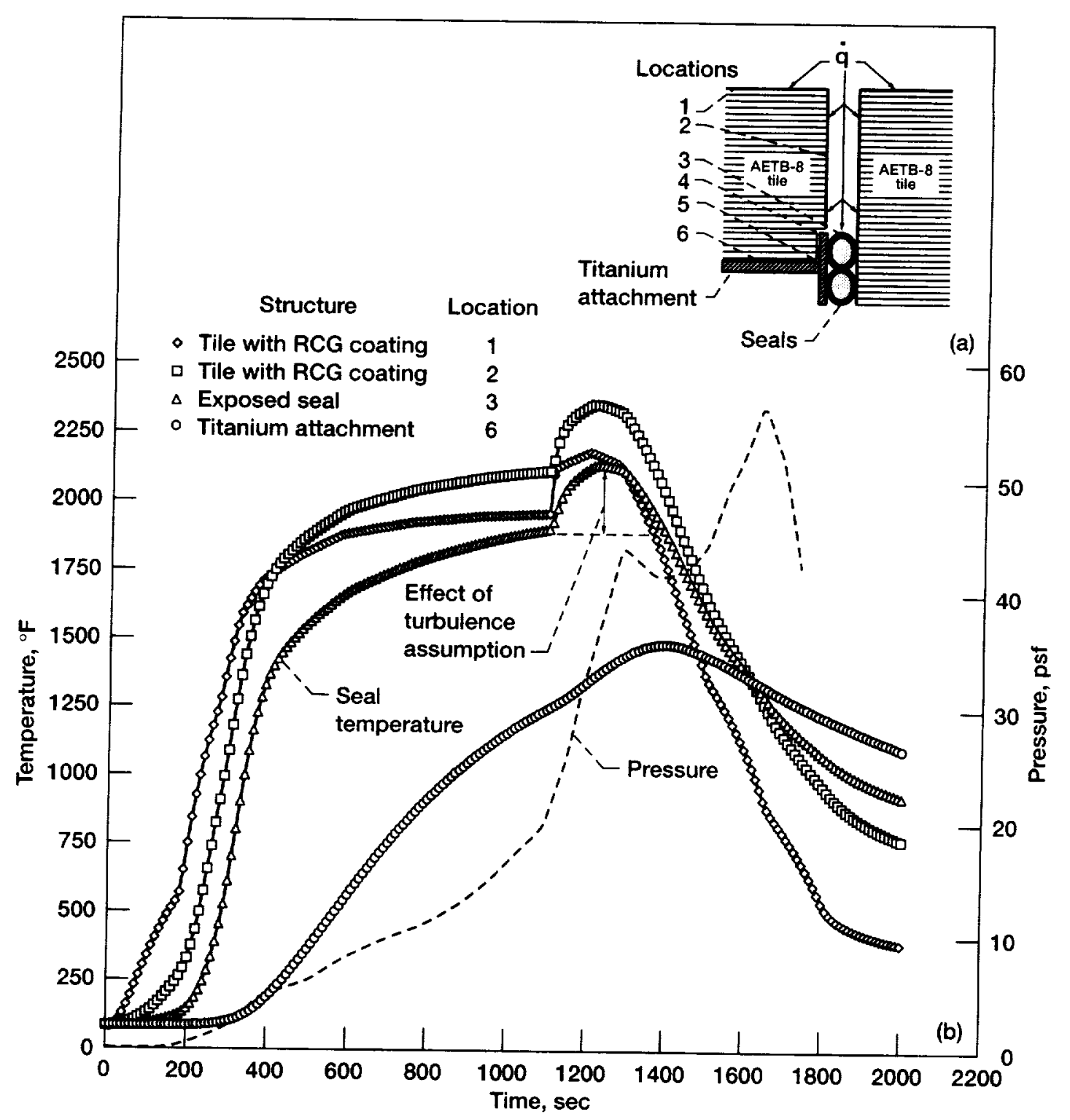

Figure 4.- Thermal analysis of rudder/fin seal. (a) Rudder/fin gap area Thermal Math Model (TMM). (b) Rudder/fin seal temperature and pressure predictions.

\section{Pressure Drop}

The maximum predicted pressure drop across the seal during vehicle re-entry is about $56 \mathrm{lbf} / \mathrm{ft}^{2}$ (outboard: high pressure) and occurs about $450 \mathrm{sec}$ after the peak heating (Fig. 4). ${ }^{3}$ To be conservative, flow tests were conducted up to the peak pressure. The pressure across the seal during peak heating is $35 \mathrm{psf}$ and occurs at $1200 \mathrm{sec}$ into the re-entry mission (Fig. 4).

\section{Resiliency}

No specific design requirement was established a priori for seal resiliency. A main requirement for the seals is that they remain in contact with the sealing surface while the vehicle goes through the maximum re-entry heating cycle. The seals must be able to accommodate differences in thermal expansion between parts adjacent to them that cause the seal gap to change size. Subsequent to the re-entry heating cycle any small thermally induced gap opening is of no consequence as the convective heating rate drops off sharply.

\section{Seal Loads/Gap}

The seals are to be installed at approximately $20 \%$ compression to ensure good sealing contact with the rudder/fin surfaces (Fig. 5). The seals will seal against Shuttle derived tile that limits the seal unit or contact load. Designers have set a unit load limit of less than 5 pounds per inch $(5 \mathrm{lb} / \mathrm{in}$.) of seal to prevent tile damage during 


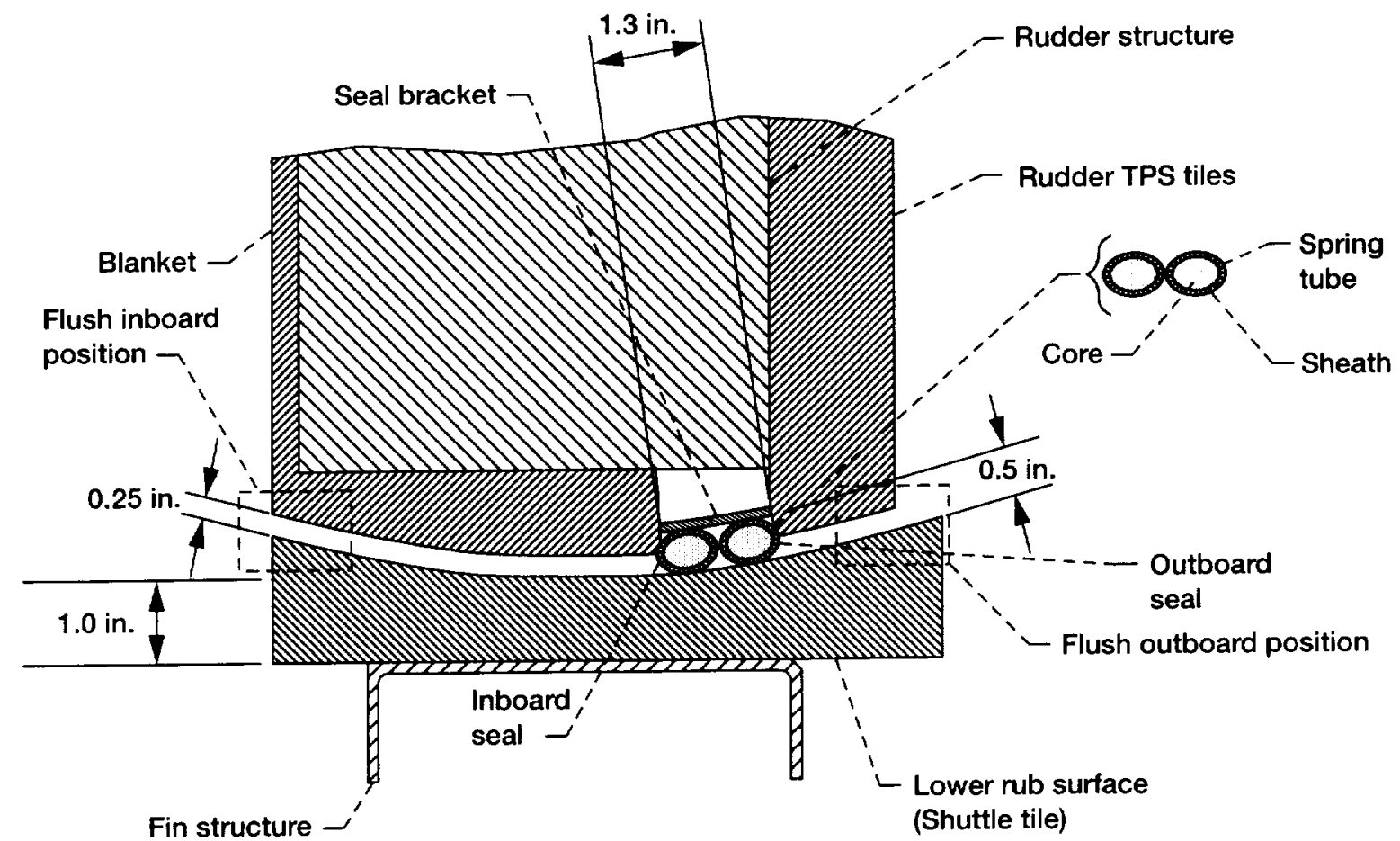

Figure 5.-Cross section of rudder/fin shelf seal location (standing aft looking forward) showing seal components.

installation or actuation. The tiles used for the rudder/fin horizontal shelf sealing surface are AETB-8 (Alumina Enhanced Thermal Barrier $-8 \mathrm{lb} / \mathrm{ft}^{3}$ density) with Reaction Cured Glass (RCG)/Toughened Uni-Piece Fibrous Insulation (TUFI) coating. A seal unit load of $5 \mathrm{lb} / \mathrm{in}$. with a contact width of $0.50 \mathrm{in}$. would apply a pressure to the tiles of $10 \mathrm{psi}$. This provides a safety factor of better than four compared to the average through-the-thickness flatwise tensile strength at room temperature for these tiles of $46 \mathrm{psi}^{3}{ }^{3}$ If the average through-the-thickness compression strength at room temperature of $58 \mathrm{psi}$ for the tiles is used in the calculations, a safety factor near six is attained for a unit load of $5 \mathrm{lb} / \mathrm{in}$. The seals are required to seal a nominal 0.25 -in. gap between the surfaces of the rudder and fin.

\section{Life/Wear Resistance}

The X-38 rudder/fin seals are only required to last for one mission and are expected to be replaced after each mission. During the single use mission, the seals must be robust enough to endure the scrubbing that they will experience in being moved across the sealing surface. In addition, as the rudder rotates to the extents of its movement the seals will experience a "scissoring" action as they are moved on to and off of the shelf sealing surface. When the seals are moved off of the fin shelf they will tend to return to an uncompressed shape. As they are moved back on to the surface and compressed again, they must be able to endure the shear forces that they will be subjected to without causing excessive loads on the rudder drive motor. The vertical hinge line seals also get scrubbed over a sealing surface as the rudder actuates, but they remain in contact with that surface throughout the mission. Candidate materials being considered for the hinge line rub surfaces include Inconel and ceramic matrix composites. Because the rudder/fin shelf seals will be exposed to more severe loading conditions, the wear resistance of these seals is examined as part of the current study.

\section{Test Apparatus and Procedures}

\section{Seal Specimens}

The seal design examined in this study had a nominal diameter of 0.62 in. (see Table I and Fig. 5). It consisted of an Inconel X-750 spring tube stuffed with Saffil batting and overbraided with two layers of Nextel 312 ceramic fibers. The Inconel wires used in the spring tube were formed from rod that was previously annealed at $2100^{\circ} \mathrm{F}$ or higher in a non-nitriding atmosphere. The Saffil batting stuffed into the Inconel spring tube had a density of $6 \mathrm{lb} / \mathrm{ft}^{3}$. This seal design will hereafter be referred to as the $6 \mathrm{pcf}$ design. The seal is currently used in several places on the Space Shuttle orbiters including the main landing gear doors, the orbiter external tank umbilical door, and the payload bay door vents. It was selected as the baseline seal design for the rudder/fin location of the $\mathrm{X}-38$. 
TABLE I - X-38 SEAL CONSTRUCTION MATRIX

\begin{tabular}{|c|c|c|c|c|c|c|c|c|c|}
\hline Seal Type & Size & \multicolumn{3}{|c|}{$\begin{array}{r}\text { Core } \\
\end{array}$} & \multicolumn{2}{|c|}{ Spring Tube } & \multicolumn{3}{|c|}{ Sheath } \\
\hline & $\begin{array}{c}\text { Diameter } \\
\text { in. }\end{array}$ & Material & $\begin{array}{c}\text { Density } \\
\mathrm{lb} / \mathrm{ft}^{3}\end{array}$ & $\begin{array}{c}\text { Measured } \\
\text { percent of } \\
\text { seal by } \\
\text { mass }(\%)\end{array}$ & Material & $\begin{array}{l}\text { Measured } \\
\text { percent of } \\
\text { seal by } \\
\text { mass }(\%)\end{array}$ & Material & $\begin{array}{c}\text { Number of } \\
\text { layers }\end{array}$ & $\begin{array}{c}\text { Measured } \\
\text { percent of } \\
\text { seal by } \\
\text { mass }(\%)\end{array}$ \\
\hline $6 \mathrm{pcf}$ & 0.620 & Saffil $^{6}$ & 6 & 12.5 & Inco X-750 & 33 & $\mathrm{NX} 312^{d}$ & 2 & 54.5 \\
\hline
\end{tabular}

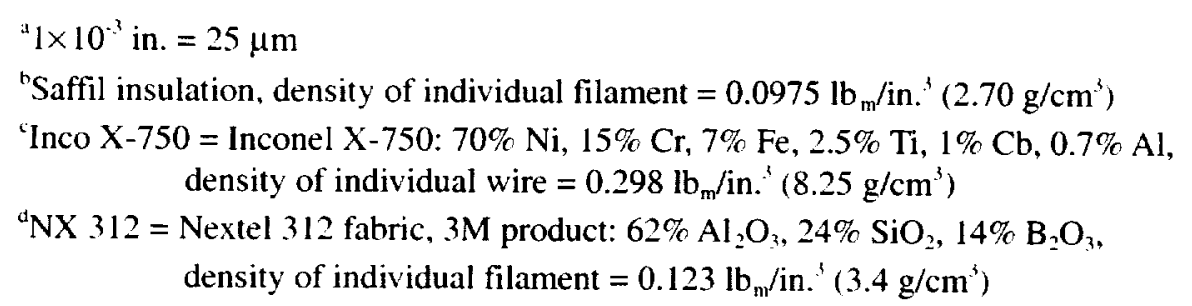

\section{Porosity Measurements}

The porosity of the 6 pcf seal design was measured using two different approaches.

Archimedes Approach - The first approach used Archimedes theory of volume displacement. This principle states that the volume of liquid that is displaced when a solid object is dropped into the liquid is equal to the volume of the solid. The porosity of the seal was determined by putting covered and uncovered seal specimens into a $100 \mathrm{ml}$ graduated cylinder partially filled with isopropyl alcohol and comparing the volume displaced by the specimen in each condition. Covering the specimens prevented alcohol from penetrating into the porous structure of the seal and allowed the cylindrical volume of the exterior of the seal to be determined. The alcohol easily wicked into the uncovered specimens and filled the voids inside of them. This allowed the volume of just the solid material in the seal to be determined. A total of four seal specimens of approximately 2.5 to 3 in. in length were tested.

These simple tests were performed in several steps. First, a short length of seal was wrapped in plastic wrap and taped closed to ensure that the plastic wrap did not unravel and that no alcohol penetrated into the seal. Care was taken in wrapping the specimen in the plastic wrap so that the wrap fit snugly around the seal but did not compress it. This ensured that the cylindrical volume of the uncompressed seal would be measured accurately. The wrapped specimen was then dropped into the graduated cylinder. The volume level of the alcohol in the cylinder was measured before and after the seal was inserted so that the difference in volume was the amount displaced by the seal ( $V_{\text {covered seal }}$ ). The specimen was then taken out of the cylinder, and the plastic wrap was removed from it. The wrap was then placed into the cylinder by itself to determine how much volume it displaced ( $\left.V_{\text {plastic wrap }}\right)$. This amount was subtracted from the volume measured for the wrapped seal to determine the actual volume that only the exterior of the seal would have displaced. Finally the unwrapped specimen was placed into the cylinder. After allowing the alcohol to absorb into the seal, the volume displaced by the material in the seal was recorded ( $V_{\text {uncovered seal }}$ ). Porosity $(\varepsilon)$ was then calculated using the following equation. where $V_{f}$ is the fiber volume ratio:

$$
\begin{aligned}
\varepsilon & =1-V_{f} \\
& =1-\left(\frac{V_{\text {uncovered seal }}}{V_{\text {covered seal }}-V_{\text {plastic wrap }}}\right)
\end{aligned}
$$

Mass/Volume Approach - A second mass/volume approach was used to corroborate the Archimedes approach and consisted of the following steps. First, overall specimen volume was determined by making precision measurements of cross-sectional dimensions of the ends of 1 in. long seal specimens compressed in a groove machined in a test block. A flat plate compressed the seal in the groove to the $20 \%$ design compression. The total volume ( $\left.\mathrm{V}_{\mathrm{Total}}\right)$ was determined by multiplying the measured seal elliptical cross-sectional area times the seal length. Second, the seal was cut open and separated into its individual components: the Saffil core, Inconel spring tube, and Nextel sheath. Each of these constituents was weighed on a precision (1 $\mathrm{mg}$ ) mass balance to determine their respective masses. (Note: Table I includes measured constituent masses as percentages of the total seal mass, for reference purposes.) Volumes of each of the constituents were then determined by dividing their masses by their respective individual fiber densities as shown in Table I. Finally the fiber volume ratio $\left(V_{f}\right)$ was found by summing the individual constituent volumes $\left(\mathrm{V}_{\mathrm{j}}\right)$ and dividing by 
the total measured volume $\left(\mathrm{V}_{\text {Total }}\right)$. Porosity $(\varepsilon)$ was determined for each of the two specimens by the following equation:

$$
\varepsilon=1-V_{\mathrm{f}}=1-\frac{\Sigma V_{\mathrm{i}}}{V_{\text {Total }}}
$$

\section{Compression Tests}

Compression tests were performed to determine seal preload and resiliency behavior at room temperature using a precision linear-slide compression test fixture. A specimen was loaded into a stationary grooved specimen holder, and an opposing plate was compressed against the specimen. The groove was rectangular in shape with a width of 0.62 in. and a depth of $0.37 \mathrm{in.} \mathrm{Stainless} \mathrm{steel}$ shims were placed in the groove behind the specimen to vary the amount of linear compression. Specimens of 1.5 to $3 \mathrm{in}$. long were tested. Specimen lengths were chosen to stay within the combined 10-lb load limit of the two $5 \mathrm{lb}$ load cells on the fixture. Longer specimens were used for tests in which the compression forces were expected to be low. The amount of compressive load on the specimen was measured versus the amount of linear compression for several load cycles. Multiple load cycles were applied to the specimen before the preload data point was recorded to remove the effects of hysteresis and permanent set that accumulate with load cycling of the specimens. Most permanent set occurred within the first four load cycles, so each test was conducted for four cycles. A pressure sensitive film mounted on the opposing plate was used to determine the contact width of the specimen as it was compressively loaded. The footprint length and width at the end of the fourth load cycle were used to calculate seal preload in pounds per square inch. The measured load versus compression data was used to determine residual interference corresponding to a given linear crush value. ${ }^{4}$ Residual interference is defined as the distance that the specimen will spring back while maintaining a load of at least $0.01 \mathrm{lb} / \mathrm{in}$. of specimen. The hardware and procedure used to perform these tests are described in detail by Steinetz, et al. ${ }^{4}$ Overall accuracy of the preload values measured using this method was calculated to be $\pm 3.4 \%$ of the value. ${ }^{5}$

Test Matrix - In the previous study by Dunlap, et al. ${ }^{3}$ compression tests were performed at compression levels of 20,25 , and $30 \%$ of the specimen's overall diameter. In the current study, compression tests were carried out at a low compression level of $10 \%$ compression to determine the resiliency and specimen preload under minimal loading conditions. In the actual rudder/fin seal application the seals are to be installed at approximately $20 \%$ compression. The low compression tests were performed to simulate conditions in which seals may become unloaded during use or take on a large permanent set due to temperature exposure. Primary and repeat compression tests were performed.

\section{Flow Tests}

Flow tests were performed on the seals in an ambient temperature linear flow fixture shown schematically in Fig. 6. The flow fixture was designed so that either single or double seals of different diameters could be tested in renovable cartridges that are inserted into the main body of the test fixture. Seals can be tested in this fixture with different seal gaps and under different amounts of linear compression.

Flow Path/Instrumentation - During flow testing pressurized air entered through an opening in the base of the fixture and passed through a plenum chamber before reaching the test seal. Air flowed through the gap between the cartridge and the cover plate, passed through the seal and its interface with the cover plate, and then flowed out
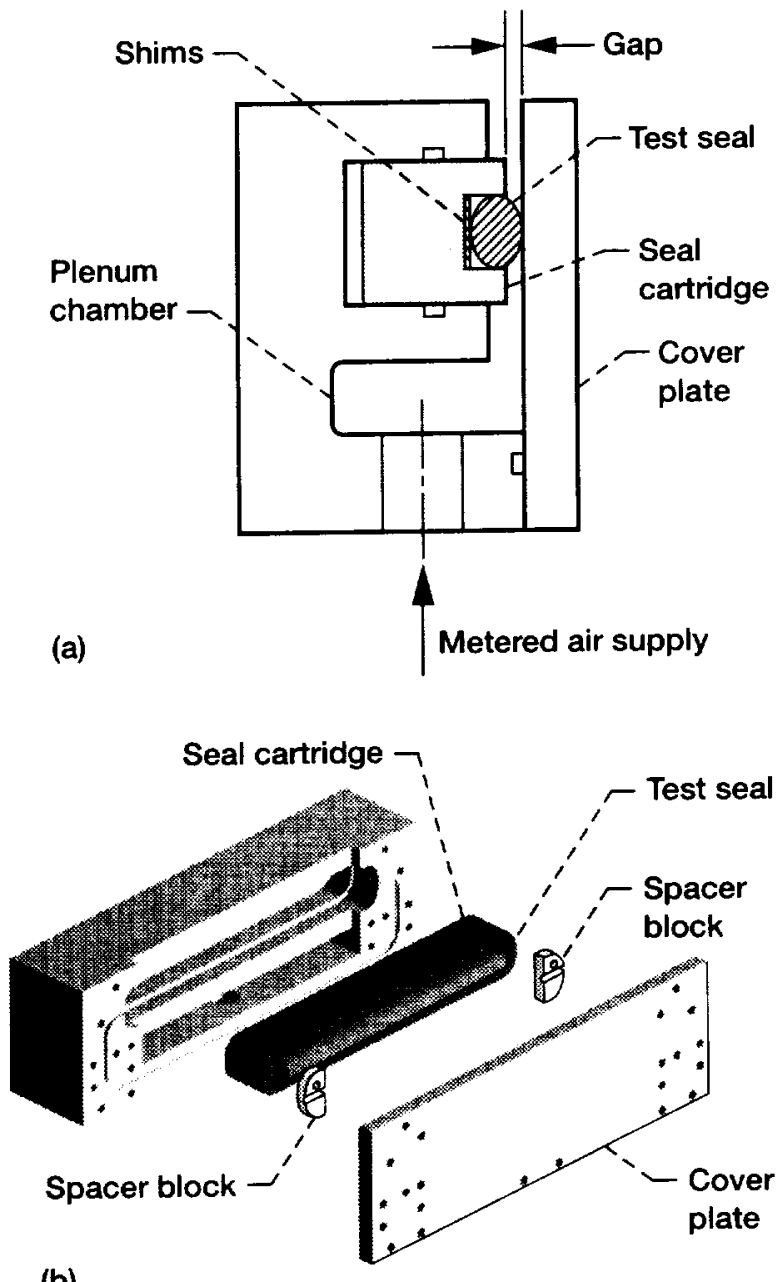

(b)

Figure 6.-Schematic of flow fixture. (a) Cross section. (b) Isometric. 
of the top of the fixture (Fig. 6a). A flow meter upstream of the flow fixture measured the amount of flow that passed through the test seal. The flow meter had a range of 0 to 100 standard liters per minute $\left(0\right.$ to $4.5 \times 10^{-3} \mathrm{lbm} / \mathrm{sec}$ ) and an accuracy of $1 \%$ of full scale. A pressure transducer ( 0 to 5 psid. $0.07 \%$ accuracy) upstream of the test seal measured the differential pressure across the seal, and a thermocouple measured the upstream temperature.

Test Fixture - Test seals of approximately 12 in. in length were mounted in the groove of a cartridge in a linear configuration. Individual cartridges were machined with a groove width for a single seal of $0.62 \mathrm{in}$. and a groove width for a double seal of 1.30 in. The amount of preload, or linear compression, was varied by placing steel shims in the cartridge groove behind the seal. For tests performed at $20 \%$ compression, the groove depth of $0.25 \mathrm{in}$. was the same as the groove depth used for the $\mathrm{X}-38$ rudder/fin seal application (Fig. 5). The cartridge was inserted into the test fixture. An O-ring sealed the perimeter of the cartridge chamber to prevent flow from passing behind the cartridge during testing. Pairs of spacer blocks secured to the cartridge at the ends of the test specimen controlled the gap width between the cartridge and the cover plate that the seals sealed against (Fig. 6b). Blocks of different thicknesses were used to vary the gap width. A small amount of RTV was placed between each spacer block and the cartridge to prevent flow from passing through this gap. Another O-ring was placed in a groove on the surface of the test fixture and into a groove in the spacer blocks to seal the plenum chamber upstrean of the test seal. The ends of this O-ring were pressed up against the ends of the test seal to prevent flow from passing around the ends of the seal. End effect leakage was minimized by exposing only the center $10 \mathrm{in}$. of the seal to the prescribed gap. One inch at each end of the 12-in. test specimen was embedded into the fixture (i.e.. gap width is zero) to reduce the effects of flow passing between the seal ends and the O-ring. Preload was applied to the test seal through an interference fit between the seal and the cover plate.

Test Matrix - Single seal flow tests were conducted on the 6 pcf seal design at compression levels of 0 and $10 \%$ of the specimen's overall diameter with a gap size of $0.25 \mathrm{in}$. Both primary and repeat flow tests were conducted at these compression levels. Double seal flow tests were also conducted at 0 and $10 \%$ compression with a 0.25 in. gap. but only primary tests were performed due to a limited amount of available seal material. As with the compression tests, the flow tests were conducted at these low compression levels to determine flow rates through the seals under minimal loading conditions. Dunlap, et al. ${ }^{3}$ performed flow tests on this seal design in a previous study at the $20 \%$ compression design point and at $25 \%$ compression.

\section{Scrub/Wear Tests}

Although the $\mathrm{X}-38 \mathrm{rudder} / \mathrm{fin}$ seal application only requires the seals to last for one mission, they do have to be robust enough to endure the scrubbing experienced while moved across the sealing surface for that mission. They also have to survive the scissoring/shearing action they will be subjected to as they engage and disengage the shelf sealing surface while the rudder pivots through its $\pm 12^{\circ}$ of rotation. To test the wear resistance of the $6 \mathrm{pcf}$ seal design, a series of tests were performed in which the seals were scrubbed over representative sealing surfaces for repeated cycles. These tests also examined the functionality and wear resistance of the seals as they were repeatedly moved on to and off of the sealing surface.

Test Fixture - The seals were evaluated in a test fixture that simulated the motion of the rudder with respect to a stationary tile sealing surface such as the fin shelf (Fig. 7). Two test seals were attached side-by-side in a groove on the top surface of a movable arm that simulated the rudder in the rudder/fin seal assembly (Figs. 3 and 5). The movable arm was pivoted on one end and mounted on the underside of a table (Fig. 7). At the other end of the arm was a roller that allowed the arm to be suspended below the table and to rotate freely with respect to the pivot. Two stops fixed to the edge of the table limited the amount of rotation of the arm to $\pm 12^{\circ}$. The seals were scrubbed against a simulated seal rub surface that was suspended through a rectangular hole cut in the center of the table. Four bolts and adjustment nuts were used to compress the rub surfaces against the test seals. The seals were compressed approximately $20 \%$ to simulate the design point on the X-38 rudder/fin. Two types of rub surfaces were used for this series of tests. The first was composed of three RCG/TUFI coated AETB- 8 tiles. The three tiles were lined up side-by-side opposite the seals along the length of the movable arm. The total length of these tiles was identical to the length of the fin shelf sealing surface on the X-38 rudder/fin. Gap fillers were stuffed into the joints between the tiles. Assembly of the scrub test fixture revealed the need for the gap fillers to be installed flush with the outer surface of the tiles to prevent sneak flows between adjacent tiles above the gap fillers. The second rub surface used for the scrub tests was a ceramic matrix composite (CMC) material called Blackglas ${ }^{\mathrm{TM}}$ that was made by Northrup Grumman. Blackglas is a silicon oxycarbide matrix reinforced with Nextel 312 fibers. ${ }^{6}$ This material is being considered for use in control surfaces of future reusable launch vehicles. Advantages that Blackglas has over the coated AETB-8 tiles are that it can be produced in larger sections thereby reducing the number of gap fillers required around the individual tiles, and it is relatively inexpensive. The surface 


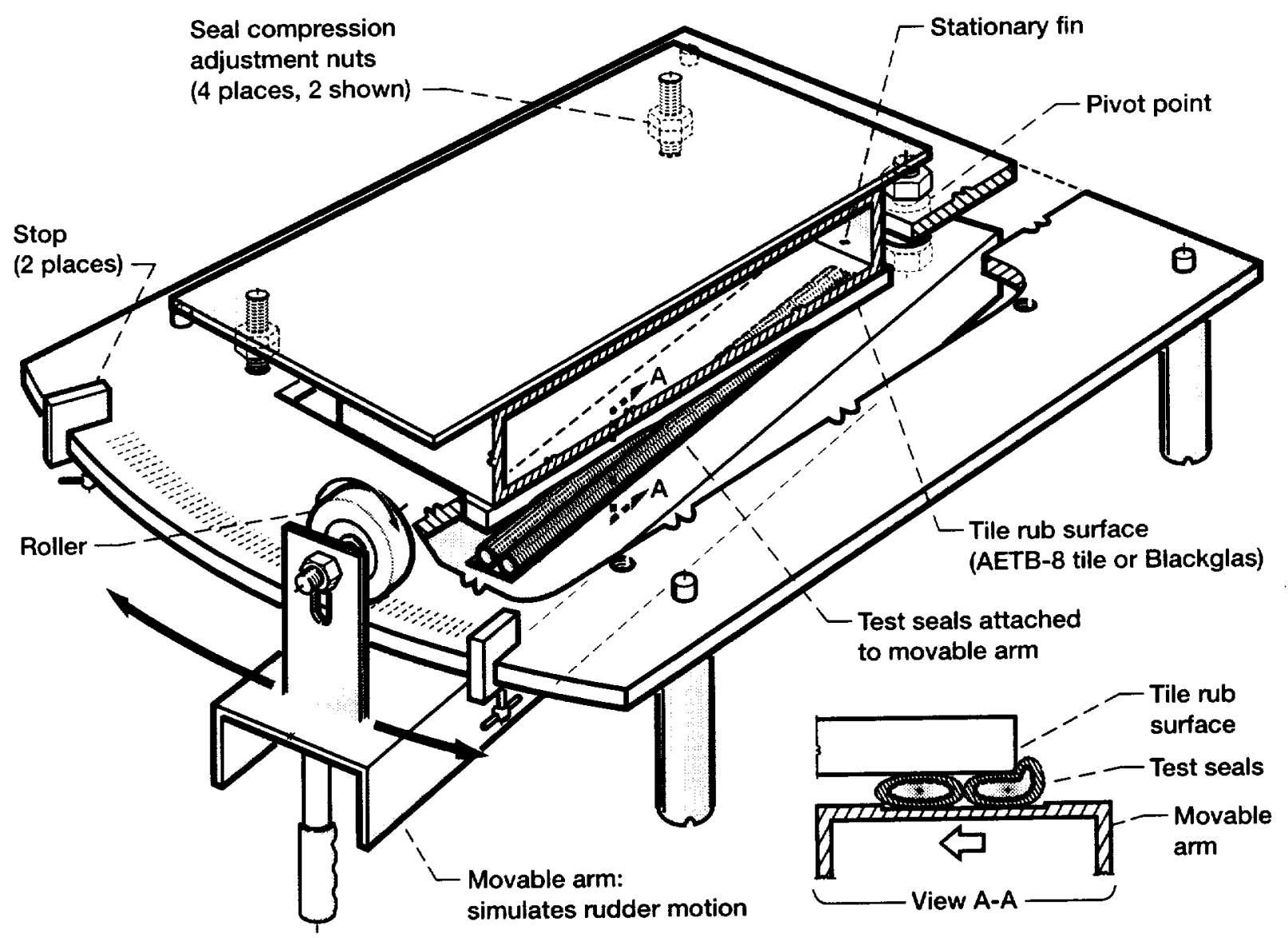

Figure 7.-Isometric of scrub/wear test fixture showing seals re-engaging the tile rub surface.

roughness of each rub surface was measured after the scrub tests using a profilometer.

During a test, the arm was rotated back and forth by hand from one stop to the other over the full range of $\pm 12^{\circ}$. Each rub surface was sized so that the seals would move off of the edges of the surface and out of contact with it as the arm was moved between the stops. This forced the seals to re-engage the rub surface as the arm rotated back toward the centerline of the rub surface (see view A-A in Fig. 7). A torque meter located at the pivot point measured the amount of torque required to rotate the arm and scrub the seals over the rub surface. The torque meter was also used to measure the amount of torque required to engage and disengage the seals as they were moved off of and back on to the rub surface.

\section{Arc jet tests}

A series of tests were performed on the 6 pcf seal design in the 20 Megawatt Panel Test Facility at NASA's Ames Research Center to simulate exposure of the seals to the extreme thermal conditions that they would experience during atmospheric re-entry. The seals were installed in a test fixture that was positioned in the test chamber such that high temperature exhaust flow passed out of the semielliptical nozzle ( 17 in. wide nozzle) of the arc jet heater and over the top surface of the test fixture. A gap in the test fixture allowed the hot air to flow down to the seals. During testing the test chamber was evacuated down to a pressure of $5 \times 10^{-2}$ torr $\left(9.67 \times 10^{-4} \mathrm{psi}\right)$ to draw flow out of the arc jet nozzle, over the test article, and through the seals. The arc jet facility has the capability of producing heat fluxes on the order of 0.5 to $75 \mathrm{BTU} / \mathrm{ft}^{2} \mathrm{sec}$ with temperatures on the top of the test article as high as $2200^{\circ} \mathrm{F}{ }^{7}$

Test Fixture - The test fixture was based on the geometry of the $X-38$ body flap (Fig. 8). Though the fixture geometry modeled the $\mathrm{X}-38$ body flap geometry, there were many similarities to the rudder/fin hinge-line seal configuration. The depth from the free stream to the seal was $1.5 \mathrm{in}$., which was in the range of the depths from the free stream to the rudder/fin hinge-line seal depending on the position of the rudder. The seal gap of $0.25 \mathrm{in}$. was identical to the rudder/fin hinge-line gap size. The model consisted of an upstream structure and a movable control surface. Test seals were placed into the gap along the hinge-line between the stationary structure and the control surface. The control surface could be actuated over a range 


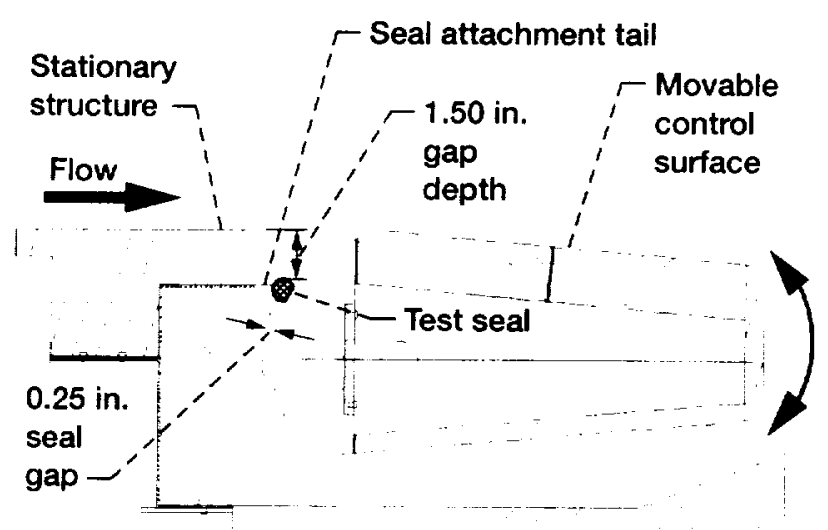

(a)

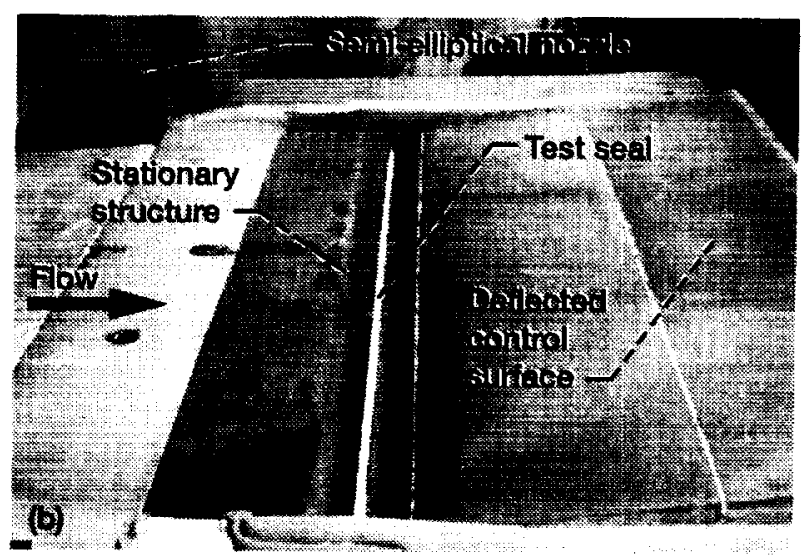

Figure 8.- Arc jet test fixture. (a) Cross section. (b) Photo of test fixture installed in arc jet tunnel with seal installed.

of 0 to $10^{\circ}$ with respect to the stationary surface, similar to the $12^{\circ}$-movement of the X-38 rudders. Raising the control surface into the arc jet flow raised the static pressure above the sealed hinge-line, deflected the high temperature flow into the seal gap, and increased seal and gap temperatures. The control surface was raised by manually turning a crank connected to a flexible shaft that pushed against a bell crank mechanism attached to the control surface. The table upon which the test fixture sat could also be adjusted to vary the angle of attack of the entire test fixture over a range of $-4^{\circ}$ (out of the flow) to $+6^{\circ}$ (into the flow) and further increase the pressure drop across the seal. Increasing the angle of attack of the entire test fixture added to the total angle that the control surface was raised into the arc jet flow so that the final control surface angle was equal to the sum of both angles (e.g., $6^{\circ}$ table angle $+10^{\circ}$ control surface angle $=16^{\circ}$ control surface deflection into flow).
The main foundation of the test fixture was a watercooled copper box into which the movable stainless steel control surface section was installed. The surfaces of these structures were covered with AETB- 8 tiles to simulate the rudder-fin thermal protection system in the X-38. The top tile on the stationary part of the test fixture was removable so that test specimens could be installed and removed from the fixture. The seal specimens used in this series of tests were 19 in. long and had a "tail" of Nextel fabric sewn on to them. This tail was clamped in between tiles in the stationary structure of the test fixture to secure the seals in place (Fig. 8a). Depending on the test conditions, the seal gap between the stationary structure and the control surface could be set at either 0.25 in. or 0.375 in. The 0.25 in. seal gap size is used in both the X-38 rudder/fin and body flap sealing applications. The seals were installed in the test fixture so that they were under $20 \%$ compression for these tests.

The test fixture was instrumented with 34 thermocouples and seven pressure taps to record temperatures and pressures upstream and downstream of the test specimens and monitor the health of the test fixture. In addition, optical pyrometers were positioned above the test chamber to record video of the temperature distribution over the top surface of the test fixture during testing. A more detailed description of the test fixture, instrumentation, and procedure used to perform these tests can be found in the final report by Newquist. et al. ${ }^{8}$

\section{$\underline{\text { Results and Discussion }}$}

\section{Porosity Measurement Results}

Porosity measurements were made on four specimens of the $6 \mathrm{pcf}$ seal design using the Archimedes approach. The porosity values measured for these specimens ranged from 83.3 to $85.2 \%$ with an average porosity of $84.4 \%$. This means that almost $85 \%$ of the volume of the seal was composed of air, and only $15 \%$ was actual material. This value was corroborated by making porosity measurements on two additional specimens using the mass/volume approach. The porosity values for these two specimens were 81.3 and $82.6 \%$ for an average porosity of $82 \%$. The mass/ volume porosity measurement was done in a compressed state that could account in-part for the slightly lower measured porosity.

The high seal porosity level is attributed primarily to the loose packing of the $6 \mathrm{pcf}$ Saffil batting. For comparison purposes, thermal barriers braided from continuous fibers have porosities in the range of 37 to $50 \% .{ }^{9}$ Porosity is important for understanding the thermal and flow response characteristics of these seals and is being used to perform thermal analyses to support the final rudder/fin seal selection. 

TABLE II - X-38 SEAL RESIDUAL INTERFERENCE, CONTACT WIDTH, UNIT LOAD.
PRELOAD, AND STIFFNESS FOR SEVERAL LINEAR CRUSH CONDITIONS

\begin{tabular}{|c|c|c|c|c|c|c|c|c|c|}
\hline Seal Type & Condition & $\begin{array}{l}\text { Diameter, } \\
\text { in. }\end{array}$ & $\begin{array}{c}\text { Nominal } \\
\text { percent } \\
\text { linear crush, } \\
\%\end{array}$ & $\begin{array}{c}\text { Linear } \\
\text { crush. } \\
\text { in. }\end{array}$ & $\begin{array}{c}\text { Residual } \\
\text { interference } \\
\text { (springback) } \\
\text { in. } \\
\end{array}$ & $\begin{array}{c}\text { Contact } \\
\text { width. } \\
\text { in. }\end{array}$ & $\begin{array}{l}\text { Unit } \\
\text { load. } \\
\mathrm{lb}_{\mathrm{r}} / \text { in. }\end{array}$ & $\begin{array}{l}\text { Preload. } \\
\text { psi }\end{array}$ & $\begin{array}{c}\text { Stiffness (k) } \\
\text { at } \% \text { linear } \\
\text { crush". } \\
\mathrm{lb}_{\mathrm{f}} / \text { in. } / \text { in. }\end{array}$ \\
\hline $6 \mathrm{pcf}$ & As-received & 0.620 & \begin{tabular}{|l|}
10 \\
20 \\
25 \\
30 \\
\end{tabular} & $\begin{array}{l}0.062 \\
0.124 \\
0.155 \\
0.186 \\
\end{array}$ & $\begin{array}{l}0.046 \\
0.084 \\
0.115 \\
0.118 \\
\end{array}$ & $\begin{array}{l}0.330 \\
0.455 \\
0.581 \\
0.692 \\
\end{array}$ & $\begin{array}{l}0.54 \\
2.01 \\
2.98 \\
4.47 \\
\end{array}$ & $\begin{array}{l}1.7 \\
4.4 \\
5.1 \\
6.4 \\
\end{array}$ & $\begin{array}{l}14 \\
39 \\
51 \\
66 \\
\end{array}$ \\
\hline $6 \mathrm{pcf}$ & $\begin{array}{c}\text { After } \\
1900^{\circ} \mathrm{F} \\
\text { exposure }\end{array}$ & 0.620 & $\begin{array}{l}20 \\
25 \\
30 \\
\end{array}$ & $\begin{array}{l}0.124 \\
0.155 \\
0.186 \\
\end{array}$ & $\begin{array}{l}0.018 \\
0.036 \\
0.029 \\
\end{array}$ & $\begin{array}{l}0.379 \\
0.452 \\
0.489 \\
\end{array}$ & $\begin{array}{l}0.91 \\
1.77 \\
1.90 \\
\end{array}$ & $\begin{array}{l}2.4 \\
3.9 \\
3.9 \\
\end{array}$ & $\begin{array}{c}58 \\
76 \\
106 \\
\end{array}$ \\
\hline
\end{tabular}

a Seal stiffness per unit inch of seal is calculated as the slope through the final two data points at the maximum amount of compression.

\section{Compression Test Results}

Table II summarizes the results of the compression tests performed on the $6 \mathrm{pcf}$ seal design. This table includes both the new data recorded for these seals in an as-received state at the low $10 \%$ compression level and data recorded previously by Dunlap, et al. ${ }^{3}$ at compression levels of 20.25 , and $30 \%$. The previously recorded data at the higher compression levels is presented for seals both in the as-received condition and after temperature exposure in a compressed state for seven minutes at $1900^{\circ} \mathrm{F}$. Values listed in this table include the measured residual interference, contact width, unit load, preload, and seal stiffness per unit inch of seal for each amount of linear compression at which the tests were performed. Figure 9 shows the load versus displacement characteristics for the $6 \mathrm{pcf}$ seal in the as-received condition for linear compressions of $0.062 \mathrm{in}$. and 0.124 in. ( 10 and $20 \%$ compression). This figure is typical of the type of data that is recorded for compression tests on the $\mathrm{X}-38$ seals in the as-received condition. It shows that the load versus displacement curves for each load cycle converge upon each other as the number of cycles increases. It also shows that the loads measured for the seals at $10 \%$ compression were much lower than those measured at $20 \%$ compression.

Residual Interference (Resiliency)-Figure 10 shows that the residual interference for the seals in an as-received condition at $10 \%$ compression followed the trend observed by Dunlap, et al. ${ }^{3}$ in which resiliency for the as-received seals increased as percent linear compression was increased. This figure also shows that exposure of the 6 pcf seal design in a compressed state at $1900^{\circ} \mathrm{F}$ for seven minutes caused a large permanent set and loss of resiliency in these seals. ${ }^{3}$

No specific design requirement was established for seal resiliency. The main requirement is that the seals remain in contact with the sealing surface while the vehicle goes through the maximum re-entry heating cycle. Results of the low (10\%) compression levels tests show that before exposure to high temperatures these seals are still resilient enough to spring back even under minimal loading conditions. An additional requirement is that the seals are able to accommodate differences in thermal expansion between parts adjacent to them that cause the seal gap to change size. Although no detailed 3-D finite element analysis of the rudder/fin seal area has yet been done to quantify the anticipated changes in seal gap size during the re-entry heating cycle of the X-38 vehicle. it is believed that these changes will be minimal because the rudders have floating fittings and attachments that were designed to compensate for thermal expansion differences between the structures around the seals.

Contact Width - As with the resiliency results, the measured contact width for the $6 \mathrm{pcf}$ seal design in an asreceived condition at $10 \%$ compression followed a trend previously observed by Dunlap. et al. ${ }^{3}$ In this case, the contact width for these seals decreased as the amount of compression on the seals was decreased. As expected. the seals did not spread and flatten out as much at lower compression levels as they did at higher compression levels. In each test, the footprint pattern left on the pressure sensitive film after a compression cycle was solid and continuous. This indicates that during a flow test continuous contact is made between the walls of the flow fixture and the seal, minimizing leakage past the specimen.

Unit Load (Load per Unit Inch)/Preload/Seal Stiffness - The results presented in Table II show that seals tested at the $10 \%$ compression level exhibited lower unit load (or load per unit inch), seal preload (or footprint contact pressure), and seal stiffness per unit inch of seal than seals compressed at 20,25 , and $30 \%$ compression. ${ }^{3}$ 


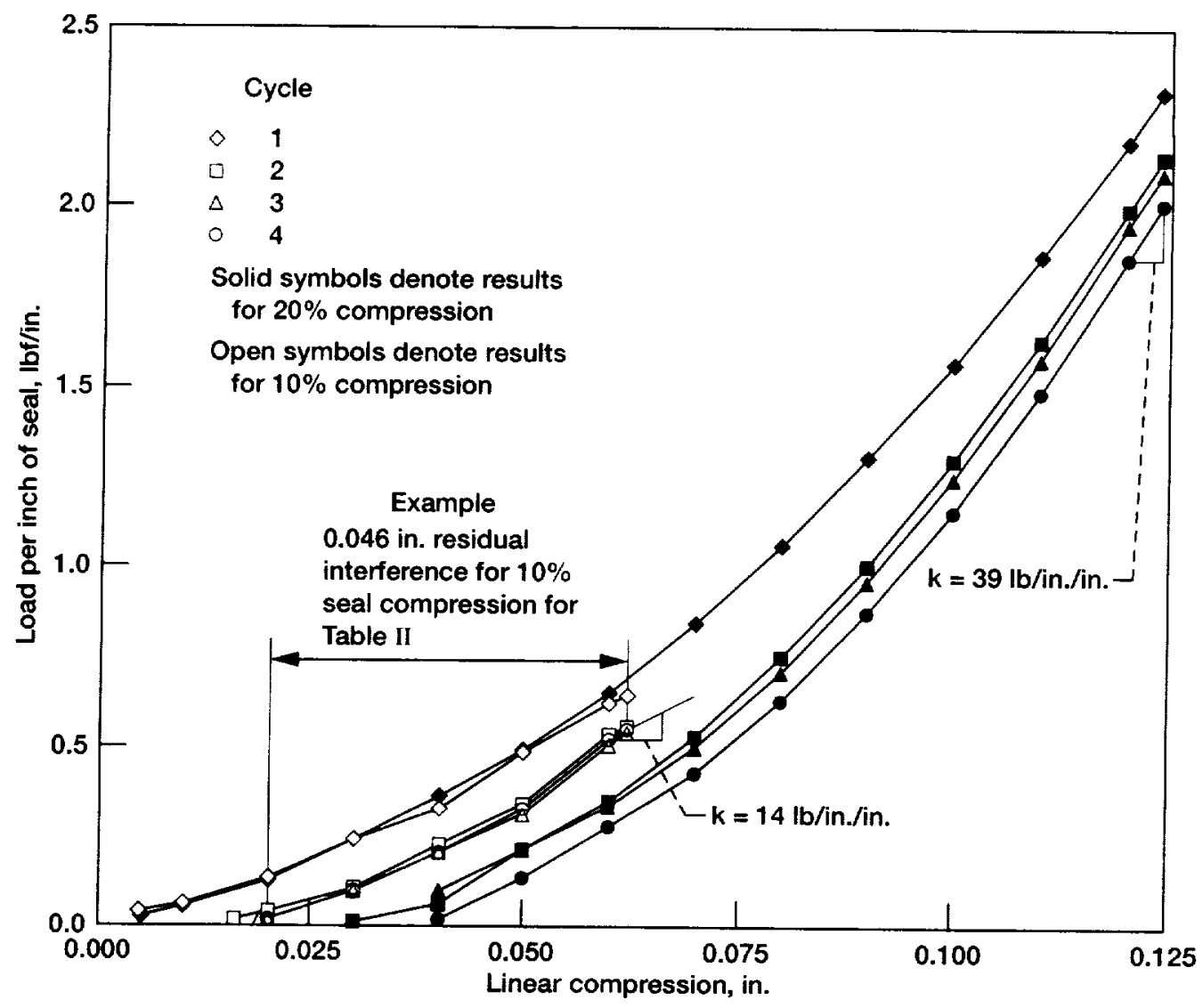

Figure 9.-Load versus linear compression data for four cycles, 6 pcf as-received seal at representative compressions of 0.062 in. (10\%) and 0.124 in. $(20 \%)$.

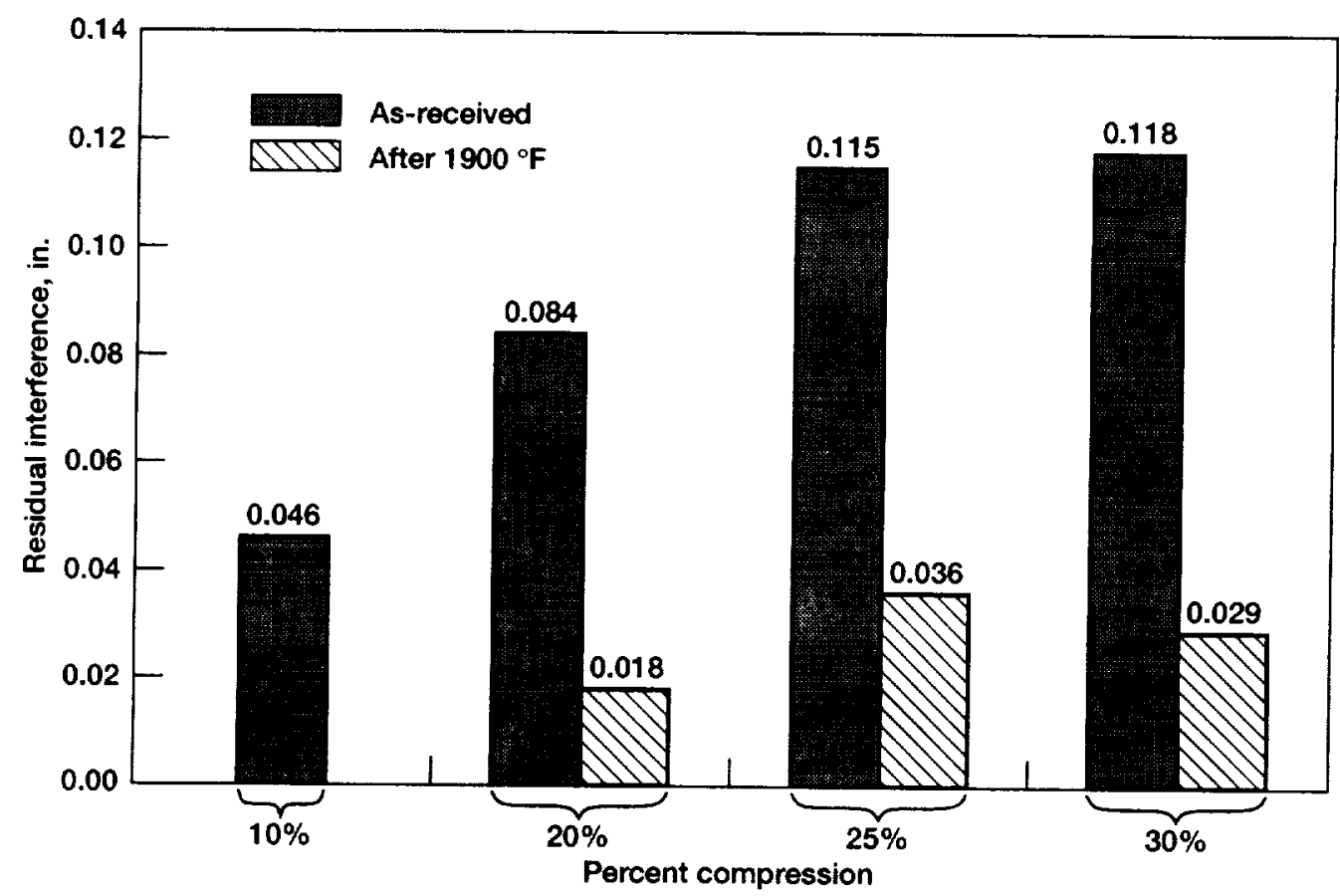

Figure 10.-The effect of temperature exposure and compression level on seal residual interference (resiliency). 
While compressed between the sealing surfaces of the rudder and the fin, the seals should not put a load of more than $5 \mathrm{lb} / \mathrm{in}$. of seal on the Shuttle thermal tiles that make up the sealing surfaces. For this application, the seals are to be installed at approximately $20 \%$ compression with a nominal 0.25 -in. gap between the surfaces of the rudder and fin. The results of the $10 \%$ compression tests followed the trends previously observed by Dunlap, et al. ${ }^{3}$ The loads measured at this low compression level were lower than those recorded at the higher compression levels. The results in Table II show that for all compression levels tested, the unit loads were below $5 \mathrm{lb} / \mathrm{in}$. of seal. The maximum seal preload, or contact pressure, that was measured was $6.4 \mathrm{psi}$ for the as-received $6 \mathrm{pcf}$ seal at $30 \%$ compression. Even at this high level of compression, the pressure that would be applied to the tiles would be seven times lower than the flatwise tensile strength of $46 \mathrm{psi}$ for the tiles and nine times lower than the compression strength. ${ }^{3}$ The results of these compression tests indicate that the 6 pcf seals meet the seal load requirements established for the rudder/fin seal application.

\section{Flow Test Results}

Flow rates for the $6 \mathrm{pcf}$ seal design in the as-received and after $1900^{\circ} \mathrm{F}$ exposure conditions are summarized in Fig. 11. This figure includes both new data recorded for these seals in an as-received state at 0 and $10 \%$ compression and for comparison purposes data recorded previously by Dunlap, et al. ${ }^{3}$ for as-received and temperature-exposed seals at compression levels of 20 and $25 \%$. The flow rates shown in this figure and in Fig. 12 are presented as the measured flow rate at room temperature at a specific pressure differential $\left(56 \mathrm{lbf} / \mathrm{ft}^{2}\right.$ (psf) for the flow rates shown in Fig. 11) divided by the length of seal exposed to flow in the test fixture ( $10 \mathrm{in}$.). Figure 12 presents flow versus pressure data for both single and double $6 \mathrm{pcf}$ seals at different compression levels for a pressure range of 0 to $202 \mathrm{psf}(144 \mathrm{psf}=1 \mathrm{psi})$. This figure shows the typical shape of the flow versus pressure curves for these seals.

Effect of Compression Level - As shown by the flow results in both Figs. 11 and 12, flow rates decreased with higher compression levels. As the amount of compression on the seals was increased from 0 to $25 \%$ the amount of

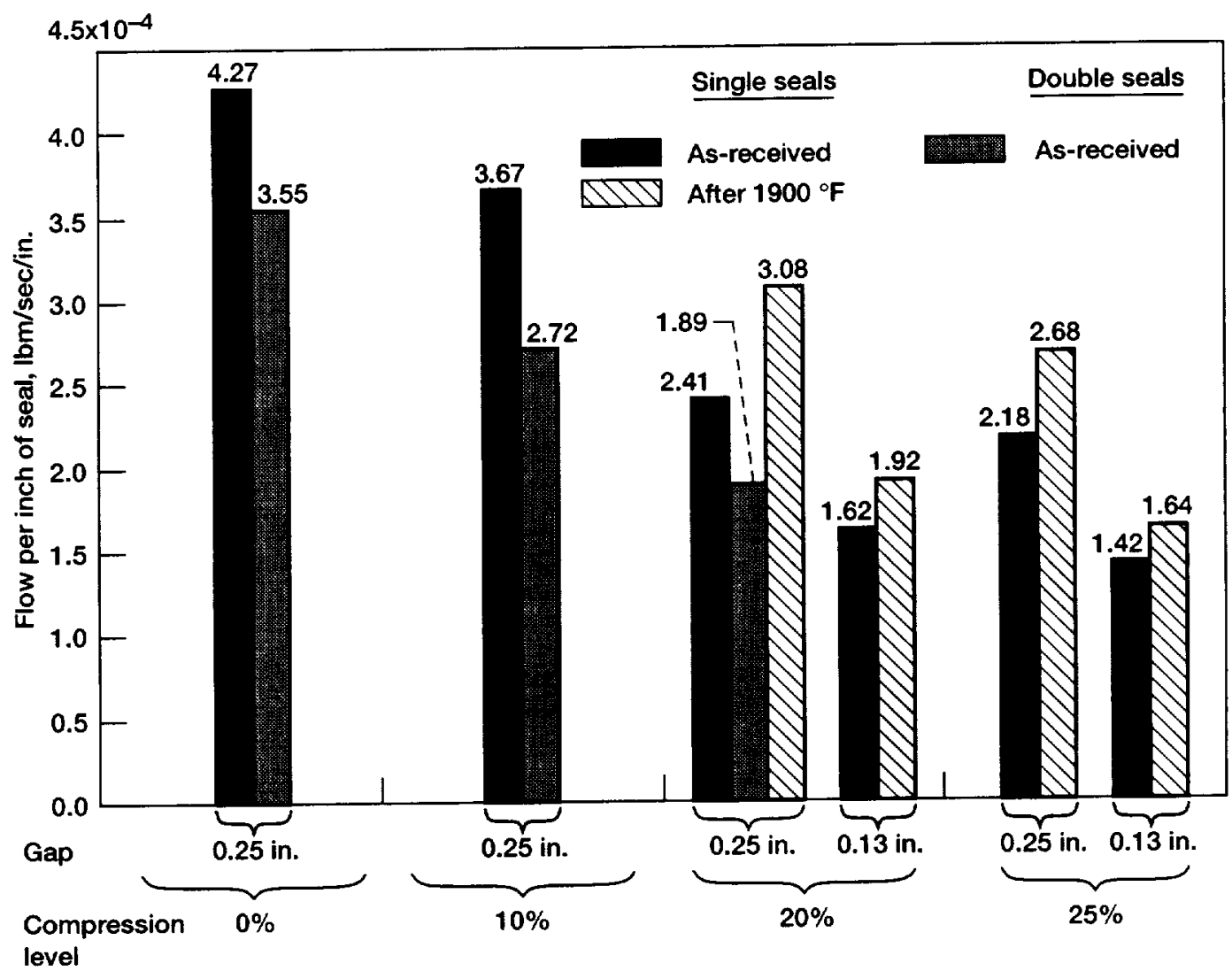

Figure 11.-The effect of number of seals, gap size, compression level, and temperature exposure on seal flow, $\Delta P=56$ psf. 


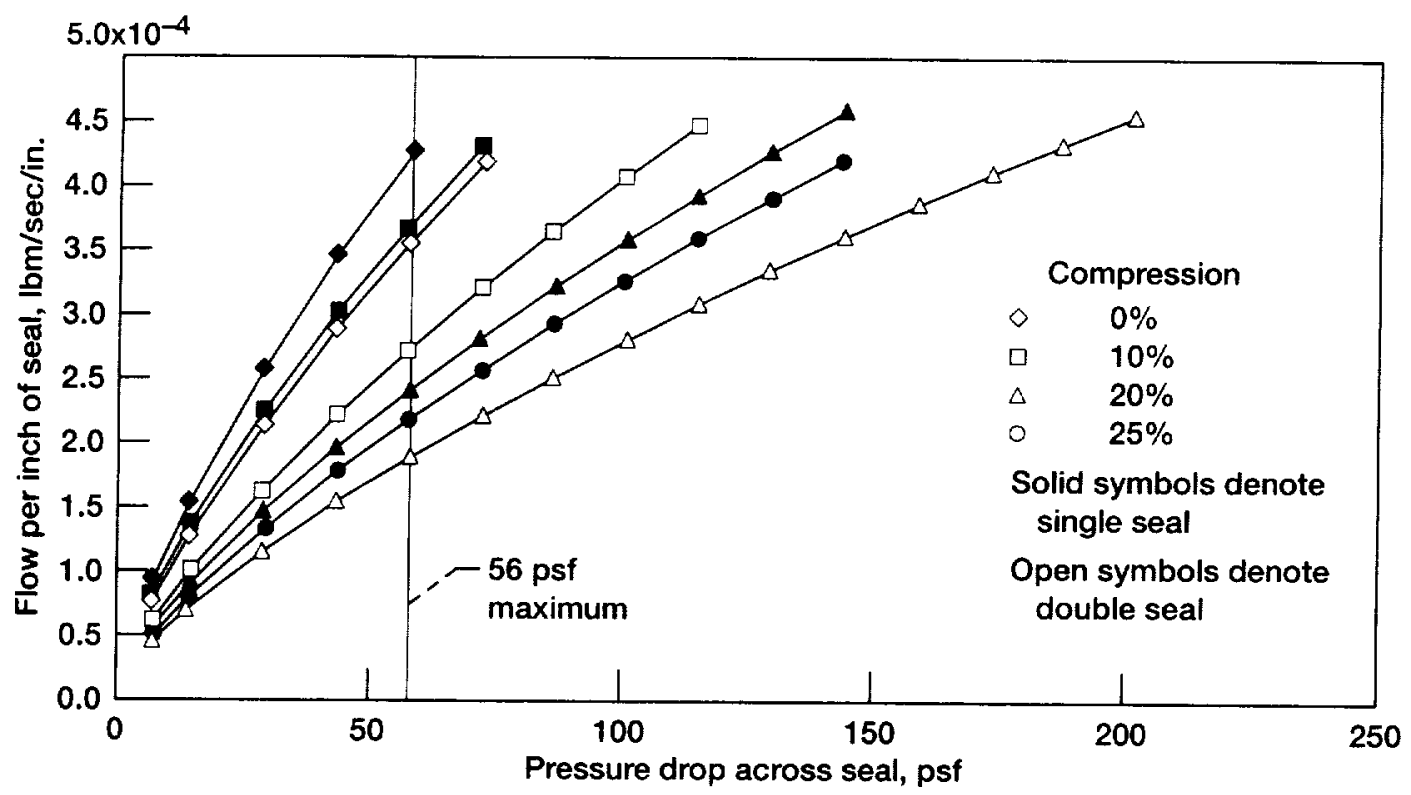

Figure 12.-Flow versus pressure data for both single and double 6 pcf seal configurations at several compression levels with a gap of 0.25 in.

flow through the seals decreased for a given gap size. This is to be expected as the act of compressing these seals closed the gaps and flowpaths in their porous structures and allowed less flow to pass through them. Seal flow rates were measured at 0 and $10 \%$ compression to determine how high the flow rates might go if the seals became unloaded. Note in Fig. 11 that the flow for a double seal at $0 \%$ compression was nearly twice that for a double seal at $20 \%$ compression. Flow rates measured at the $0 \%$ compression level provide an upper flow limit for the ongoing seal thermal analyses.

Effect of Single vs. Double Seals -Flow rates through a double seal configuration were lower than those for a single seal at 0,10 , and $20 \%$ compression (Figs. 11 and 12). Addition of a second seal into the flow path caused a reduction in flow through the seals in the range of 17 to $26 \%$ as compared to the flow rates through single seals at the same compression level and gap size. Although the second seal caused a drop in flow rates, it did not cut the flow in half. This type of behavior in multiple seal flow tests was observed previously by Steinetz, et al. ${ }^{5}$ In Fig. 12 it is interesting to note that flow rates for two seals at $0 \%$ compression are slightly lower than those for a single seal at $10 \%$ compression. Thus, addition of a second seal with basically no preload against it provides a similar amount of flow blocking capability as a single seal under $10 \%$ compression. A second seal also provides redundancy should one of the two seals experience damage.

\section{Scrub/Wear Test Results}

An initial set of tests was conducted in which the $6 \mathrm{pcf}$ seal design was scrubbed over Northrup Grumman Blackglas and RCG/TUFI coated AETB-8 tile rub surfaces for a couple of cycles to determine the torque required to rotate the compressed seals over these surfaces. The results of these tests are shown in Table III. For the Blackglas tiles, the torque required to rotate the compressed seals over the rub surface was in the range of 300 to $305 \mathrm{in} . \mathrm{lb}$. The torque required to rotate the compressed seals over the RCG/TUFI coated AETB- 8 tiles was between 700 and $800 \mathrm{lb}$-in., more than twice the torque measured in moving the seals over the Blackglas material. The roughness of each rub surface was measured after the tests were completed. As shown in Table III, the surface roughness of the coated AETB- 8 tile was about $60 \%$ higher than the roughness of the Blackglas tile when the midpoint roughness values for each material are compared ( $544 \mu \mathrm{in}$. for coated AETB- 8 tile versus $337 \mu \mathrm{in}$. for the Blackglas tile). This difference in surface roughness helps explain why the torque required to rotate the compressed seals against the rub surfaces was more than twice as large for the coated AETB- 8 tile as compared to the Blackglas tile.

The next set of tests that was performed involved cyclic wear testing in which the seals were repeatedly scrubbed over three RCG/TUFI coated AETB-8 tiles that composed the rub surface. As mentioned previously, this is the material that the tiles will seal against in the X-38 
TABLE III - TORQUE RESULTS FOR SCRUB TESTS AGAINST DIFFERENT RUB SURFACES WITH CORRESPONDING SURFACE ROUGHNESSES

\begin{tabular}{|c|c|c|}
\hline Rub surface & $\begin{array}{c}\text { Torque to rotate } \\
\text { compressed seal } \\
\text { (in.-lb) }\end{array}$ & $\begin{array}{c}\text { Post test } \\
\text { surface } \\
\text { roughness } \\
(\mu \text { in. RMS) }\end{array}$ \\
\hline Northrup Grumman Blackglas & $300-305$ & $282-392$ \\
\hline RCG/TUFI coated AETB-8 Tile (no sanding) & $700-800$ & $515-574$ \\
\hline RCG/TUFI coated AETB-8 Tile (sanded) & $380^{2}$ & $303-331$ \\
\hline
\end{tabular}

aTorque with only two tiles installed

rudder/fin shelf seal application. These tests included moving the seals off of the edge of the rub surface so that they lost contact with it and then rotating them back onto the surface to re-engage it. After the seventh scrub cycle, inspection of the seals showed broken fibers and evidence of abrasion. Broken Nextel fibers were spread over the area in which the seals were swept over the tiles. Based on these results, the two tiles closest to the pivot point were sanded in an attempt to make them smoother and limit the amount of abrasion that they were causing in the seals. The third tile (farthest from the pivot point) was left in its asfabricated condition. Scrub cycles eight (8) through one hundred $(100)$ were then conducted using this tile rub surface configuration. Inspection of the seal after the 100 th scrub cycle revealed significant deterioration of the seal where it contacted the unsanded tile (Fig. 13a). The outer Nextel sheath layer was ripped and eroded so that the Inconel spring tube was exposed and started to scrape on the unsanded tile surface. The seal was still in good condition in the areas where it had rubbed against the two sanded tiles. At this point, the unsanded tile was removed and scrub cycles 101 through 500 were conducted with a tile rub surface consisting of the two remaining smooth tiles. Tile and seal inspections were conducted every 100 cycles (i.e., 200th, 300th, 400th, 500th) during this sequence of testing. Seal condition after the 500th cycle indicated continued wear with the surface sheath layer breaking down. Subsequently an additional 500 scrub cycles were conducted. The seals were not inspected during this test sequence until completion of the 1000th scrub cycle. Inspection of the seal after the 1000 th cycle showed that the outer sheath layers were partially worn through with the Inconel spring tube exposed (Fig. 13b). The surface roughness of the sanded AETB- 8 tile was measured after the 1000 th cycle was completed, and values in the range of 303 to $331 \mu \mathrm{in}$. were recorded (Table III). This range is much lower than the 515 to $574 \mu \mathrm{in}$. roughness range measured for the non-sanded tiles. Sanding the tiles reduced the amount of friction between the seals and the rub
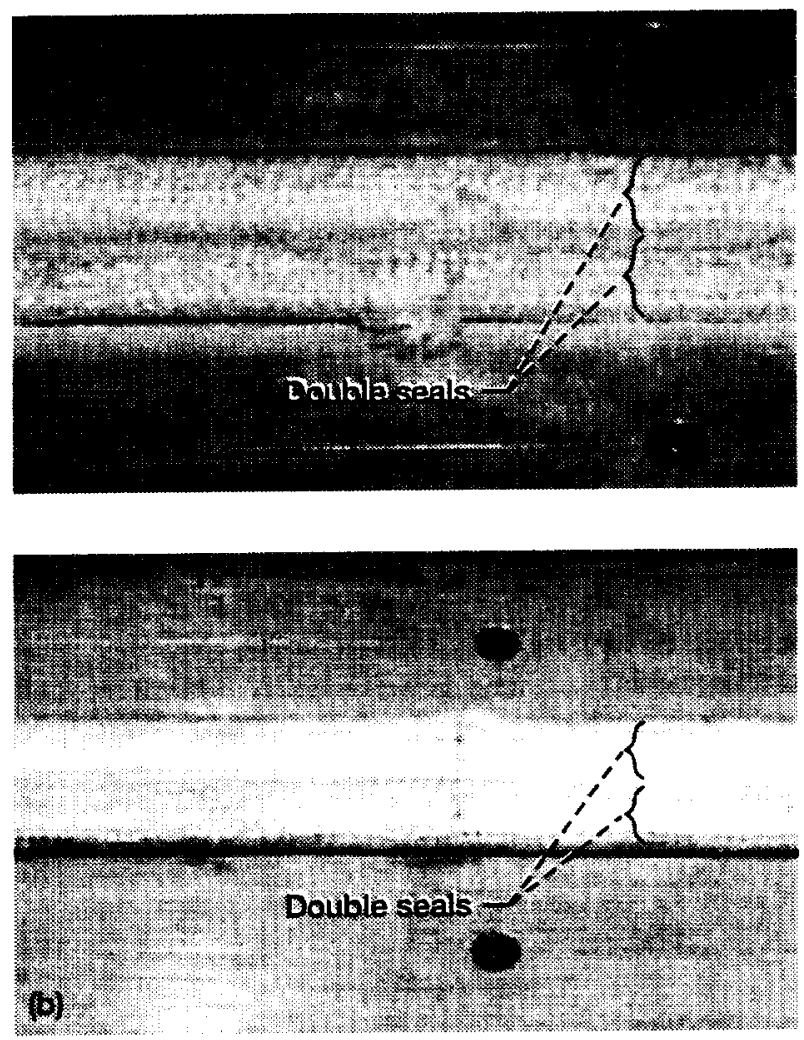

Figure 13.-Photos of seals after (a) 100 scrub cycles against unsanded RCG/TUFI coated AETB-8 rub surface. (b) 1000 scrub cycles against sanded RCG/TUFI coated AETB-8 rub surface.

surface and allowed the seals to endure many more scrub cycles with limited damage.

Although the rudder/fin seals for the $\mathrm{X}-38$ vehicle are only required to last for one mission, they still have to be robust enough to endure large scrubbing motions incurred during control surface checkouts and flight maneuvers in addition to small amounts of dithering during flight operations. The seals should also not cause excessive loads on the rudder drive motor as they are rotated and scrubbed 
against the fin shelf sealing surface. These wear tests provided feedback on whether or not the seals met these requirements. Observation of the seals while they were scrubbed over the rub surface revealed that they were able to disengage and re-engage the edges of the tiles satisfactorily. They remained securely attached to the movable arm and did not roll out of the groove that they were installed in. Torque values recorded for the scrub tests were all well within the drive motor limits ( $10,500 \mathrm{in}$.-lb at rotation speed of 30 degrees per second) ensuring that the rudders of the $X-38$ can be actuated with the seals installed. Results of these tests also showed that sanding the tiles to reduce their roughness enabled the seal to endure the 1000 cycle scrub test. The current plan for the $\mathrm{X}-38$ rudder/fin seal is to use sanded $\mathrm{RCG} / \mathrm{TUFI}$ coated AETB- 8 tiles for the horizontal shelf rub surface.

\section{Arc Jet Test Results}

The data presented in this section is sample data from an extensive 12 test series of runs performed on several different seal designs under a variety of test conditions. Details of the complete test program funded by NASA Glenn will be published in a final report by Newquist, et al. 8

Qpen Gap Test - The results of an arc jet test performed with no seal installed in the test fixture are shown in Fig. 14. This test (Test \#12 in the series of tests) served as a baseline to determine how hot the open gap in the fixture would get with no seal installed. The open gap was designed to be nominally 0.25 in. wide. However, gap measurements performed during the test program indicated that the gap decreased with increasing control surface angle from $0.288 \mathrm{in}$. at the $0^{\circ}$ position to $0.260 \mathrm{in}$. at $10^{\circ}$. The test was performed with the overall test fixture (table) angled up into the arc jet flow at a $6^{\circ}$ angle. The control surface was initially fixed at its baseline $0^{\circ}$ position (parallel to the upstream stationary portion of the test fixture) and held there while a steady arc jet flow was established over the fixture until the top surface temperature was stable at about $2200^{\circ} \mathrm{F}$ (maximum heating conditions). It was held at $0^{\circ}$ for $39 \mathrm{sec}$ under these conditions. The control surface was then rotated upward into the stream an additional $2^{\circ}$ and held in that position for the remainder of the test. Including the $6^{\circ}$-angle of the overall test fixture, the control surface total angle into the flow was 8 degrees. After $23 \mathrm{sec}$ in this configuration, portions of the test fixture became too hot, and the test was ended.

Figure 14 shows that the temperature on the top surface of the fixture was held at about $2220^{\circ} \mathrm{F}$ for the duration of the $62 \mathrm{sec}$ test. The temperature inside the seal gap at a position 0.5 in. above the usual seal location reached $2230{ }^{\circ} \mathrm{F}$ while the control surface was at its $0^{\circ}$ position and peaked at $2240^{\circ} \mathrm{F}$ after the control surface was rotated upward by $2^{\circ}$. Note that the gap temperature was actually $20^{\circ} \mathrm{F}$ higher than the temperature recorded in the arc jet flow on the top surface of the test fixture. One possible source of this higher gap temperature could have been instrumentation error for the Type R thermocouples that measured these temperatures. Type R thermocouples have an error of approximately $2.7^{\circ} \mathrm{F} .{ }^{10} \mathrm{Thus}$, for the two thermocouples being compared, at most $6^{\circ} \mathrm{F}$ ( 2 thermocouples $\times 3^{\circ} \mathrm{F}$ ) of the $20^{\circ} \mathrm{F}$ could be due to instrumentation

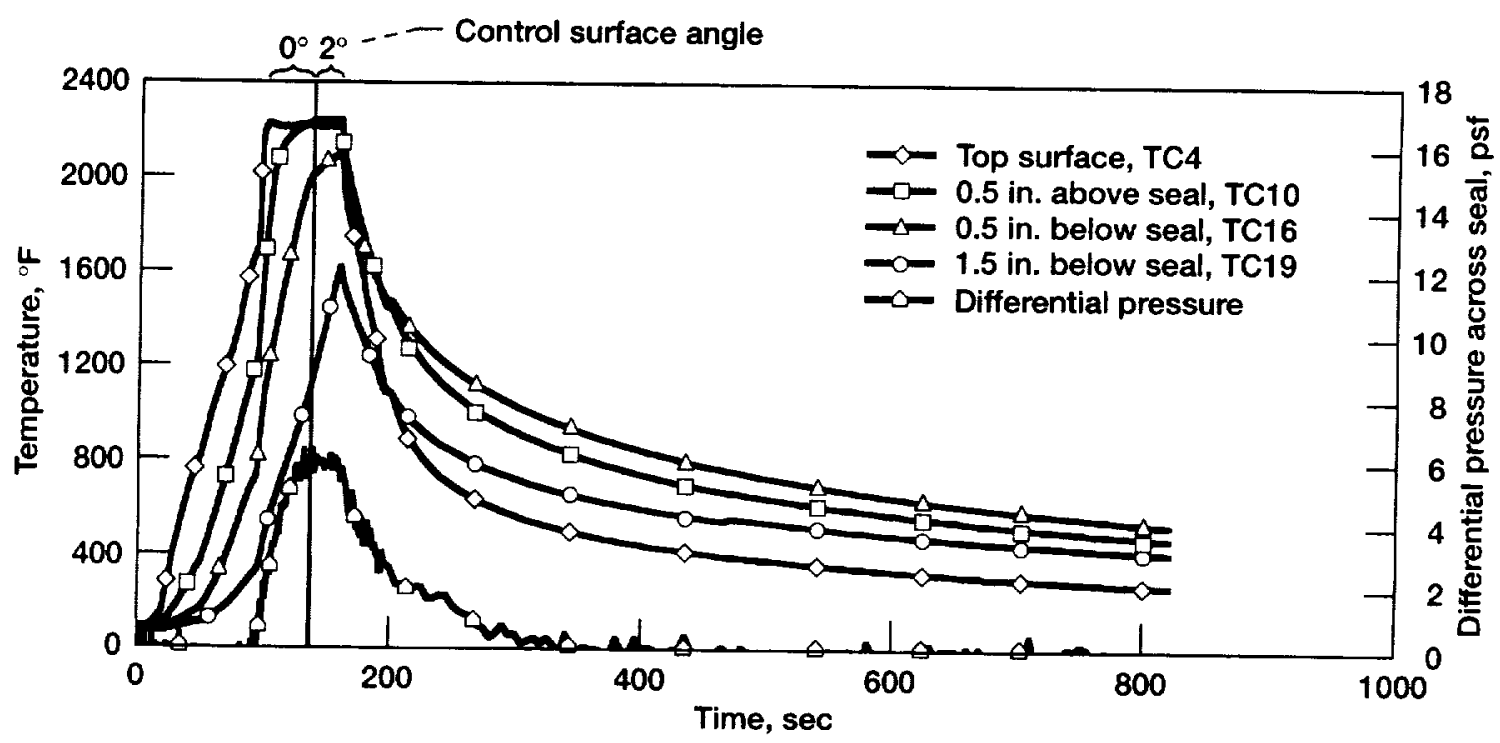

Figure 14.-Temperatures and pressure differential measured during arc jet test with no seal installed (test \#12), 6 degree table angle, 0 and 2 degree control surface angles, and 0.25 in. nominal gap. (Note that the symbols on the graph are given for identification only; data were recorded every 1 sec.) 
error. The remaining temperature difference is likely due to re-radiation of heat between the walls of the gap and a decrease in radiative cooling of the gap surfaces due to a reduced view factor in the gap. The gap temperature $0.5 \mathrm{in}$. below where the seal would have been located reached $2010^{\circ} \mathrm{F}$ before the control surface was adjusted (i.e., $0^{\circ}$ control surface angle) and $2100^{\circ} \mathrm{F}$ by the end of the test (i.e., $2^{\circ}$ control surface angle).

The temperature 1.5 in. below the seal position rose to $1620^{\circ} \mathrm{F}$ by the end of the test. These gap temperatures were quite high and have the potential of damaging low temperature structures inside the seal gap if no seals were present. Although no seal was installed in the gap for this test, the temperature drop across the seal location can be evaluated as the difference between the temperatures recorded 0.5 in. above and below where the seal would have been. Before the control surface was rotated, the temperature drop across the seal location was about $220^{\circ} \mathrm{F}$. After the control surface was rotated, the temperature drop decreased to $140^{\circ} \mathrm{F}$ by the end of the test.

Over the 62 sec test, the average pressure differential across the seal location was about 5.6 psf (Fig. 14). This pressure drop was measured using static pressure taps 0.5 in. above and below the usual seal location. This pressure differential shows that flow did indeed pass through the seal gap. Note that this pressure was $16 \%$ of the predicted 35 psf pressure drop across the seal at the $1200 \mathrm{sec}$ maximum heating point during $\mathrm{X}-38$ vehicle re-entry (Fig. 4). Without a seal installed in the rudder/fin gap during X-38 re-entry, the higher pressure differentials across the open gap would cause more mass flow into the gap and create a potential for even higher gap temperatures than those recorded during this test. These results confirm that a seal is required in the rudder/fin gap to reduce heat fluxes into the gap. The study by Wong, et al. ${ }^{2}$ also predicted high temperatures in an open rudder/fin gap and emphasized the need for a seal in the gap to prevent excessive local heat fluxes on these structures.

Arc Jet Test with Seal Installed-Figure 15 shows the results of an arc jet test (Test \#5 in the series of tests) with a seal installed in the gap. The 6 pcf seal was installed at $20 \%$ compression in a nominal 0.25 in. gap. As in the open gap test, this test was performed with the overall test fixture (table) rotated up into the arc jet flow at a $6^{\circ}$-angle. The control surface was again fixed at its baseline $0^{\circ}$ position when the test began and held there while a steady arc jet flow was established over the fixture until the top surface temperature reached a steady state temperature condition of about $2200^{\circ} \mathrm{F}$. The control surface was held at $0^{\circ}$ for $38 \mathrm{sec}$ and then rotated upward in $2^{\circ}$ increments approximately every $45 \mathrm{sec}$ until it was angled $10^{\circ}$ with respect to the upstream stationary portion of the test fixture. It was held in this final position for an additional $41 \mathrm{sec}$ before the test was ended. Including the $6^{\circ}$-table angle, the final control surface position was rotated upward $16^{\circ}$ into the arc jet flow. The total time spent at maximum heating conditions $\left(2200^{\circ} \mathrm{F}\right.$ on the top surface) was $263 \mathrm{sec}$. This time is comparable to the $250 \mathrm{sec}$ of peak heating for the rudder/fin seals predicted between 1100 and 1350 sec of the X-38 re-entry mission (Fig. 4). During the arc jet test the average pressure differential across the

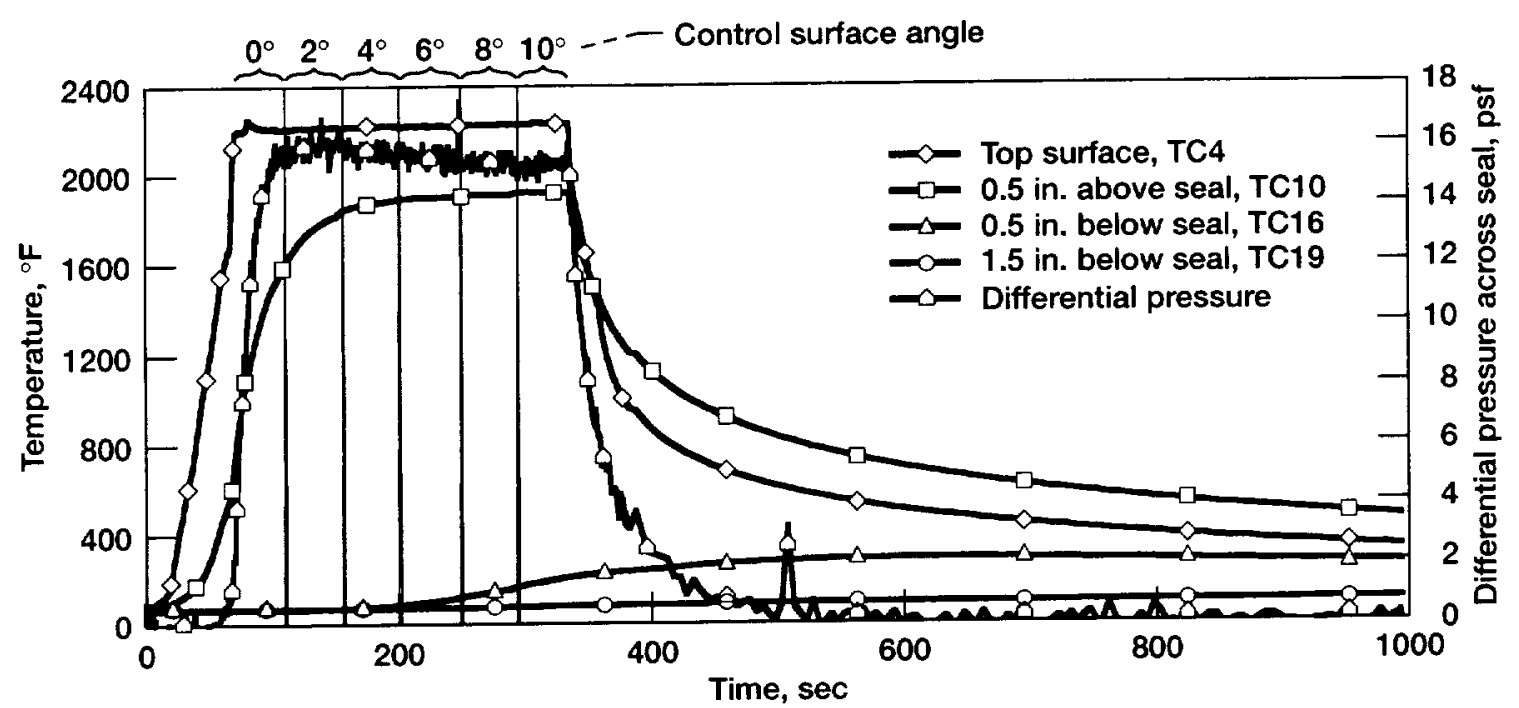

Figure 15.-Temperatures and pressure differential measured for arc jet test with seal installed at $20 \%$ compression (test \#5), 6 degree table angle, $0,2,4,6,8$, and 10 degree control surface angles, and 0.25 in. nominal gap. (Note that the symbols on the graph are given for identification only; data were recorded every 1 sec.) 
seal during maximum heating conditions was $15.6 \mathrm{psf}$, indicating that flow passed through the seal (Fig. 15). This pressure level is about $44 \%$ of the 35 psf pressure predicted at the $1200 \mathrm{sec}$ maximum heating point during $X-38$ vehicle re-entry (Fig. 4).

The average temperature on the top surface of the test fixture during maximum heating conditions was $2220^{\circ} \mathrm{F}$. With a seal installed in the gap, the temperature $0.5 \mathrm{in}$. above the seal did not get as hot as in the open gap test. At this station. the peak temperature reached $1610^{\circ} \mathrm{F}$ while the control surface elevon was at its $0^{\circ}$ position, $620^{\circ} \mathrm{F}$ less than the temperature reached during the open gap test over the same amount of time. As the control surface was rotated upward into the arc jet flow stream in $2^{\circ}$ increments. the temperature $0.5 \mathrm{in}$. above the seal gradually continued to rise until it reached a peak temperature of $1920^{\circ} \mathrm{F}$ by the end of the test.

The conditions for the test with the seal installed were more extreme than those for the open gap test. The period of time spent under maximum heating conditions was only $62 \mathrm{sec}$ for the open gap test, while the test with the seal installed lasted for $263 \mathrm{sec}$, more than three minutes longer. In addition, the elevon was rotated up into the arc jet flow more during the test with the seal installed $\left(16^{\circ}\right)$ than for the open gap test $\left(8^{\circ}\right)$, deflecting more high temperature flow into the gap. For the sealed gap test the peak temperature 0.5 in. above the seal at test end was $320^{\circ}$ lower than the peak temperature for the open gap test. Clearly, installing a seal in the gap created a flow block that limited the amount of heat convected into gap under these extreme test conditions.

Temperature Drop Across Seal - Temperatures recorded $0.5 \mathrm{in}$. below the installed seal were much lower than those recorded in the open gap test. During the maximum heating conditions, the peak temperature reached was only $207^{\circ} \mathrm{F}$, resulting in a temperature drop across the seal of about $1710^{\circ} \mathrm{F}$ (Fig. 15). This is much larger than the $140^{\circ} \mathrm{F}$ temperature drop across the seal location for the open gap test. Once the arc jet was shut off, the temperature $0.5 \mathrm{in}$. downstream of the installed seal continued to rise over the next few minutes peaking at $288^{\circ} \mathrm{F}$. This was caused by the amount of time it took to conduct heat through the test fixture to the seal location. Temperatures recorded $1.5 \mathrm{in}$. below the installed seal barely increased during this test, reaching a peak temperature of $101^{\circ} \mathrm{F}$. Again, this is much lower than the peak temperature of $1620^{\circ} \mathrm{F}$ measured at the same location in the open gap tests.

The seal specimen that was used for this test survived the arc jet exposure. A limited amount of damage was caused to the outer Nextel sheath layers of the seal due to limited actuation (less than 10 cycles) of the control surface during the test. Some broken fibers were seen spread over the surface of the control surface in areas where the seal was wiped over the surface. but the seal was generally in good condition after the test.

It is clear from the results of these tests that installation of a seal in the gap of the test fixture caused a large temperature and pressure drop across the seal location as compared to an open gap condition. The seal acted as an effective thermal barrier limiting heat fluxes through the seal gap and minimizing temperature increases downstream of the seal during maximum heating conditions. The pressure differential measured across the seal was $44 \%$ of the 35 psf maximum pressure predicted at the $1200 \mathrm{sec}$ maximum heating point during $\mathrm{X}-38$ vehicle re-entry (Fig. 4). The larger pressure drop during re-entry could potentially cause more flow through the seal with higher temperatures downstream of the seal. However. only one seal was used in these tests whereas two seals will be installed side-by-side in the X-38 rudder/fin seal application. This will drop the amount of flow through the gap as shown by the results of the flow tests presented earlier in this paper. The competing effects of the higher differential pressure across the seal and the addition of a second seal in the gap will need to be evaluated either analytically or by performing additional arc jet tests. As mentioned previously, the authors plan to perform additional thermal analyses that include flow through the seals under these extreme conditions to determine what effect this has on the predicted maximum seal temperature and temperature drop across double seals.

\section{Summary and Conclusions}

NASA is currently developing the $\mathrm{X}-38$ vehicle that will demonstrate the technologies required for a potential crew return vehicle (CRV) for the International Space Station. This vehicle will serve both as an ambulance for medical emergencies and as an evacuation vehicle for the manned space station. The X-38 control surfaces require seals to limit hot gas ingestion and transfer of heat to underlying low-temperature structures to prevent overtemperature of these structures and possible loss of the vehicle. NASA JSC and GRC are working together to develop the seals that are to be used in the rudder/fin interfaces of the X-38. The main objectives of the current study were to characterize the baseline design for these seals under simulated minimal load conditions, examine the wear resistance of the seals, and evaluate seal performance under re-entry conditions simulated in an arc jet facility.

The baseline rudder/fin seal examined in this study was a 6 pcf thermal barrier used in several locations on the Space Shuttle. Room temperature seal compression tests were performed at low compression levels to determine load versus linear compression, preload, contact area, 
stiffness, and resiliency characteristics under low load conditions. Seal flow tests were conducted at ambient temperature to examine their leakage characteristics at low compression levels in an as-received condition. Seal scrub tests were performed to examine durability and wear resistance and to recommend surface treatments required to maximize seal wear life. Arc jet tests were performed to experimentally determine anticipated seal temperatures for representative flow boundary conditions (pressures and temperatures) under simulated vehicle re-entry conditions. Based on the results of the current tests, the following conclusions are made:

1. Unit loads and contact pressures for the as-received $6 \mathrm{pcf}$ seal were below the $5 \mathrm{lb} / \mathrm{in}$. and $10 \mathrm{psi}$ limits for all compression levels that were tested. Low unit loads and contact pressures are required to limit the loads on the Shuttle thermal tiles that the seals contact in the rudder/fin shelf location.

2. Flow rates through an unloaded (e.g., $0 \%$ compression) double seal arrangement were twice those of a double seal compressed to the $20 \%$ design compression level. These flow rates will be included in future thermal analyses to predict the effect of flow through the seals on overall seal temperatures.

3. The seals survived a 1000 cycle ambient temperature scrub test. They were able to disengage and re-engage the edges of the rub surface tiles while being scrubbed over relatively rough RCG/TUFI coated AETB-8 tile surfaces. The seals remained securely attached and did not roll out of the groove in which they were seated. Reducing the roughness of the tiles via sanding helped reduce seal wear over the 1000 cycle scrub test.

4. Results of the arc jet tests confirmed the need for seals in the rudder/fin gap location. Installation of a single seal in the gap of the test fixture caused a large temperature drop $\left(1710^{\circ} \mathrm{F}\right)$ across the seal location as compared to an open gap condition $\left(140^{\circ} \mathrm{F}\right)$. The seal acted as an effective thermal barrier limiting heat convection through the seal gap and minimizing temperature increases downstream of the seal during maximum heating conditions.

\section{References}

${ }^{1}$ Bilstein. R.E.. Orders of Magnitude: A History of the NACA and NASA, 1915-1990. NASA SP-4406, 1989. pp. 84-85.

${ }^{2}$ Wong, H. and Kremer, F.G.J., "Numerical Assessment on the Heating of the Rudder/Fin Gap in X-38 Space Vehicle,"International Symposium on Atmospheric Reentry Vehicles and Systems, Arcachon, France, March 1999, pp. 1-10.

${ }^{3}$ Dunlap, P.H., Steinetz, B.M. and Curry, D.M., "Rudder/Fin Seal Investigations for the X-38 Re-Entry Vehicle," NASA TM-210338/REV1, AIAA-2000-3508. November 2000.

${ }^{4}$ Steinetz, B.M., Adams, M.L., Bartolotta. P.A., Darolia, R., and Olsen, A.. "High Temperature Braided Rope Seals for Static Sealing Applications," NASA TM107233 rev., July 1996, also Journal of Propulsion and Power, Vol. 13, No. 5. 1997, pp. 675-682.

${ }^{5}$ Steinetz, B.M. and Adams, M.L., "Effects of Compression. Staging, and Braid Angle on Braided Rope Seal Performance," NASA TM-107504, July 1997, also Joumal of Propulsion and Power, Vol. 14, No. 6, 1998, pp. 934-940.

${ }^{6}$ Hurwitz, F.I. and Meador.M.A.B., "Tailoring Silicon Oxycarbide Glasses for Oxidative Stability," Joumal of Sol-Gel Science and Technology, Vol. 14, 1999, pp. 75-86.

${ }^{7}$ Newquist, C.W., Verzemnieks, J., Keller, P.C.. and Shorey, M.W., "Advanced High Temperature Structural Seals," NASA CR-210522, November 2000.

${ }^{8}$ Newquist, C.W., Verzemnieks, J., Keller, P.C., and Shorey, M.W., Final Report for Contract Number F3361595-D-3203, Delivery Order Number 0014, "Advanced High Temperature Structural Seals."

${ }^{9}$ Steinetz, B.M. and Dunlap, P.H., "Development of Thermal Barriers for Solid Rocket Motor Nozzle Joints." NASA TM-209278, AIAA-99-2823, June 1999.

${ }^{10}$ Omega Engineering, Inc., The Temperature Handbook, $2 I^{\text {st }}$ Century Edition, Omega, Stamford. CT, 1999, p. Z-210. 
Public reporting burden for this collection of information is estimated to average 1 hour per response, including the time for reviewing instructions, searching existing data sources, gathering and maintaining the data needed, and completing and reviewing the collection of information. Send comments regarding this burden estimate or any other aspect of this collection of intormation, including suggestions for reducing this burden, to Washington Headquarters Services, Directorate for Information Operations and Reports, 1215 Jefferson Davis Highway, Suite 1204. Arlington, VA 22202-4302, and to the Office of Management and Budget, Paperwork Reduction Project (0704-0188). Washington, DC 20503.

\section{\begin{tabular}{l|l|l|} 
1. AGENCY USE ONLY (Leave blank) & 2. REPORT DATE & 3. REPORT TYPE AND DATES COVERED
\end{tabular}}

4. TITLE AND SUBTITLE

July 2001

Technical Memorandum

Further Investigations of Control Surface Seals for the X-38 Re-Entry Vehicle

\section{AUTHOR(S)}

WU-706-85-37-00

Patrick H. Dunlap, Jr., Bruce M. Steinetz. Donald M. Curry,

Charles W. Newquist, and Juris Verzemnieks

\section{PERFORMING ORGANIZATION NAME(S) AND ADDRESS(ES)}

National Aeronautics and Space Administration

John H. Glenn Research Center at Lewis Field

Cleveland, Ohio 44135-3191

5. FUNDING NUMBERS

8. PERFORMING ORGANIZATION

REPORT NUMBER

E- 12834

9. SPONSORINGMONITORING AGENCY NAME(S) AND ADDRESS(ES)

National Aeronautics and Space Administration

Washington, DC 20546-0001

10. SPONSORINGMONITORING

AGENCY REPORT NUMBER

NASA TM-2001-210980

AIAA-2001-3628

11. SUPPLEMENTARY NOTES

Prepared for the 37th Joint Propulsion Conference and Exhibit cosponsored by the AIAA, ASME, SAE, and ASEE, Salt Lake City, Utah. July 8-11. 2001. Patrick H. Dunlap. Jr., and Bruce M. Steinetz, NASA Glenn Research Center; Donald M. Curry, NASA Johnson Space Center, Houston, Texas; Charles W. Newquist and Juris Verzemnieks, The Boeing Company. Seattle, Washington. Responsible person, Patrick H. Dunlap, Jr., organization code 5950, $216-433-$ 6374.

\begin{tabular}{l|l} 
12a. DISTRIBUTION/AVAILABILITY STATEMENT & 12b. DISTRIBUTION CODE
\end{tabular}

Unclassified - Unlimited

Subject Category: 37

Distribution: Nonstandard

Available electronically at http://gltrs.grc.nasa.gov/GLTRS

This publication is available from the NASA Center for AeroSpace Information. 301-621-0390.

13. ABSTRACT (Maximum 200 words)

NASA is currently developing the $X-38$ vehicle that will be used to demonstrate the technologies required for a potential crew return vehicle (CRV) for the International Space Station. This vehicle would serve both as an ambulance for medical emergencies and as an evacuation vehicle for the Space Station. Control surfaces on the X-38 (body flaps and rudder/fin assemblies) require high temperature seals to limit hot gas ingestion and transfer of heat to underlying low-temperature structures to prevent over-temperature of these structures and possible loss of the vehicle. NASA's Johnson Space Center (JSC) and Glenn Research Center (GRC) are working together to develop and evaluate seals for these control surfaces. This paper presents results for compression. flow, scrub, and arc jet tests conducted on the baseline X-38 rudder/fin seal design. Room temperature seal compression tests were performed at low compression levels to determine load versus linear compression, preload, contact area. stiffness, and resiliency characteristics under low load conditions. For all compression levels that were tested, unit loads and contact pressures for the seals were below the $5 \mathrm{lb} / \mathrm{in}$. and $10 \mathrm{psi}$ limits required to linut the loads on the adjoining Shuttle thermal tiles that the seals will contact. Flow rates through an unloaded (i.e.. $0 \%$ compression) double seal arrangenent were twice those of a double seal compressed to the $20 \%$ design compression level. The seals survived an ambient temperature $100 \times 1$ cycle scrub test over relatively rough Shuttle tile surfaces. The seals were able to disengage and re-engage the edges of the rub surface tiles while being scrubbed over them. Arc jet tests were perfonned to experimentally determine anticipated seal temperatures for representative flow boundary conditions (pressures and temperaturesi under simulated vehicle re-entry conditions. Installation of a single seal in the gap of the test fixture caused a large temperature drop $\left(1710^{\circ} \mathrm{F}\right)$ across the seal location as compared to an open gap condition $\left(140^{\circ} \mathrm{F}\right)$ confirming the need for seals in the rudder/fin gap location. The seal acted as an effective thermal barrier limiting heat convection through the seal gap and minimizing temperature increases downstream of the seal during naximum heating conditions.

14. SUBJECT TERMS Seals: Flow; Design: Test: Re-entry vehicle 25

\begin{tabular}{|c|c|}
\hline $\begin{array}{c}\text { 17. SECURITY CLASSIFICATION } \\
\text { OF REPORT } \\
\text { Unclassified }\end{array}$ & $\begin{array}{c}\text { 18. SECURITY CLASSIFICATION } \\
\text { OF THIS PAGE } \\
\text { Unclassified }\end{array}$ \\
\hline
\end{tabular}
19. SECURITY CLASSIFICATION OF ABSTRACT Unclassified



